\title{
The Demand for Tobacco in Post-Unification Italy*
}

\author{
Carlo Ciccarelli ${ }^{\dagger}$ \\ Università di Roma "Tor Vergata" \\ Gianni De Fraja $a^{\ddagger}$ \\ University of Nottingham \\ Università di Roma "Tor Vergata" and C.E.P.R.
}

April 4, 2013

\begin{abstract}
This paper studies the demand for tobacco products in post-unification Italy. We construct a very detailed panel dataset of yearly consumption in the 69 Italian provinces from 1871 to 1913, and use it to estimate the demand for tobacco products. We find support for the Becker and Murphy (1988) rational addiction model. The empirical analysis further suggests that, in the period considered, tobacco was a normal good in Italy: its consumption increased with income. Subsequently, we consider separately the components of aggregate tobacco (fine-cut tobacco, snuff, cigars, and cigarettes), and tentatively suggest that habit formation was a stronger factor on the persistence of consumption than physical addiction. The paper ends by showing that the introduction of the Bonsack machine in the early 1890s did not coincide with changes in the structure of the demand for tobacco, suggesting cost driven technological change.
\end{abstract}

JEL Numbers: D11, N33, I18

Keywords: Smoking, Italian Kingdom, Rational Addiction, Panel Data

*We would like to thank Brian A'Hearn, Stefano Fenoaltea, Jesse Matheson, Alessandro Nuvolari, Pierpaolo Pierani, Ludovic Renou, James Rockey, Silvia Tiezzi, Chris Wallace, Jacob Weisdorf, an anonymous referee of this journal and the audience at the April 2012 FRESH meeting in Pisa and at the Banca d'Italia for precious suggestions.

†Università di Roma "Tor Vergata", Dipartimento di Economia e Finanza, Via Columbia 2, I-00133 Rome, Italy; email: carlo.ciccarelli@uniroma2.it

${ }^{\ddagger}$ Nottingham School of Economics, Sir Clive Granger Building, University Park, Nottingham, NG7 2RD, UK, Università di Roma "Tor Vergata", Dipartimento di Economia e Finanza, Via Columbia 2, I-00133 Rome, Italy, and C.E.P.R., 90-98 Goswell Street, London EC1V 7DB, UK; email: defraja@economia.uniroma2.it. 


\title{
The Demand for Tobacco in Post-Unification Italy
}

\author{
April 4, 2013
}

\begin{abstract}
This paper studies the demand for tobacco products in post-unification Italy. We construct a very detailed panel dataset of yearly consumption in the 69 Italian provinces from 1871 to 1913, and use it to estimate the demand for tobacco products. We find support for the Becker and Murphy (1988) rational addiction model. We also find that, in the period considered, tobacco was a normal good in Italy: aggregate tobacco consumption increased with income. Subsequently, we consider separately the four types of products which aggregate tobacco comprises (fine-cut tobacco, snuff, cigars, and cigarettes), and tentatively suggest that habit formation was a stronger factor on the persistence of consumption than physical addiction. The paper ends by showing that the introduction of the Bonsack machine in the early 1890s did not coincide with changes in the structure of the demand for tobacco, suggesting cost driven technological change.
\end{abstract}

JEL Numbers: D11, N33, I18

Keywords: Smoking, Italian Kingdom, Rational Addiction, Panel Data 
Tobacco, divine, rare superexcellent tobacco, which goes far beyond all panaceas, potable gold and philosopher's stones, a sovereign remedy to all diseases. (Robert Burton, Anatomy of Melancholy, 1621).

\section{Introduction}

This paper is a detailed study of the demand for tobacco products in the Italian Kingdom from 1871, soon after unification, to the eve of World War I. Today, consumers of tobacco are under intense pressure to reduce its use. This pressure takes a wide variety of forms, from public awareness campaigns to regulation, from taxes to prohibition, but was likely to be completely absent in Italy in the period we study. ${ }^{1}$ Beside its historical interest, our work thus allows to form an idea of how prices, income and patterns of addiction affect the demand for tobacco products in the absence of the confounding influence of government intervention.

Our data on consumption of tobacco in the period considered forms a new dataset, which we constructed from the very detailed accounts of 43 years of tobacco sales, carefully divided into four product groups, snuff, fine-cut tobacco, cigars and cigarettes, in each of the 69 provinces in which Italy was divided.

We begin the paper by applying the theoretical framework provided by the rational addiction model, due to Becker and Murphy (1988), to the aggregated panel obtained adding up the consumption of the various products, by province and year. This framework assumes that consumers understand the effect of current consumption on the future utility of their future tobacco consumption, and, to the extent that they can anticipate future exogenous changes, in, say, taxes or prices, they adjust their current consumption accordingly. Empirically,

\footnotetext{
${ }^{1}$ After sporadic and often short-lived attempts to ban or reduce tobacco consumption (Sloan 2002, p. 149, Alston et al. 2002), public health campaigning grew steadily in intensity after World War II, following the first influential studies of the health effects of smoking such as the 1953 American Cancer Society and British Medical Research Council report, and the 1964 US Surgeon General's Report. Early analysis of these campaigns have suggested potentially unexpected effects (eg. Sumner 1971, Atkinson and Skegg 1973, Warner 1977, Schneider et al. 1981, and Engleman 1987, for a survey). This might be due to the compounding of addiction and the cumulative effect of staggered shocks and each petering out with time. An example of the more recent evaluations of the effects of specific policies is Frieden et al. (2005).
} 
we follow the strategy proposed by Becker et al. (1994), and refined by Baltagi and Griffin (2001), to include forward levels of consumption, appropriately instrumented, among the explanatory variables for current consumption. Our main findings lend support to the rational addiction model: both forward and lagged consumption have significant effects on current consumption. With regard to prices, our econometric analysis suggests a short run price elasticity of -0.19 , a long run price elasticity with a higher absolute value of -2.76 , and an implicit intertemporal rate of substitution of 0.29, as shown in Table 2 below. These figures are plausible and robust to different econometric techniques and model specifications. They are also in line with the corresponding magnitudes for existing studies in different countries and in different time periods. ${ }^{2}$

Besides price, the other main determinant of demand for tobacco (or indeed any goods) is income. While our tobacco data are very accurate, there are no measures of income at the same level of disaggregation, and we need to resort to appropriate proxies. We use yearly provincial data on the total revenues raised by a group of taxes, classified as "Business taxes", which together constitute a reasonable index of economic prosperity at the time, and whose definition and collection was consistent across the country. ${ }^{3}$ Using this proxy, the income elasticity of consumption is 0.09 in the short run, and 1.3 in the long run. This remains positive and statistically significant and robust to alternative proxies and different econometric specifications. We therefore conclude that tobacco was a normal good in Italy at the time, as one would expect given the country's economic backwardness. Most recent studies of demand for tobacco products obtain instead a negative income elasticity (see the survey by Chaloupka and Warner 2000, p. 1548), identifying smoking as an inferior good. Our paper therefore would suggest that the barrage of awareness anti-smoking campaigns and other government intervention might have had the effect of changing income elasticity from positive to negative, turning tobacco from a normal good to an inferior one. Unlike income, education appears to have had the same effect on

\footnotetext{
${ }^{2}$ A survey is Chaloupka and Warner (2000); examples of more recent work are Escario and Molina (2001), DeCicca et al. (2002), Farrelly et al. (2005), Lance et al. ( 2004), and Adda and Cornaglia (2006).

${ }^{3}$ We do have statistical reconstructions of annual national income, and perhaps more importantly, we also have estimates of regional GDP in some years. Encouragingly, both these measures correlate strongly with the corresponding measure obtained from our proxy.
} 
tobacco consumption than it has today: lower education leads to higher usage.

The richness of our dataset allows us to investigate two additional topics of interest, namely the source of addiction and the link between consumer demand and technological improvements in production.

The reason why some people consume tobacco day after day, and find it difficult to give up, might be addiction or it might be habit. According to Frenk and Dar (2000), addiction is physical dependence, "progressive changes in the central nervous system, which, ultimately, lead to a state where not taking the drug is highly unpleasant" (Frenk and Dar 2000, p. 14, their emphasis); a habit is the routine performance of tasks or behaviours, which becomes ingrained and automatic through repetition; habits can be good, washing one's hands before eating, or bad, picking one's nose, or smoking a cigar (pp. 19-20). The four different types of tobacco products which make up our dataset, snuff tobacco, rolling and pipe tobacco (fine cut), cigars, and cigarettes, have arguably distinct modes of consumption, and this can help disentangle addiction from habit. To this aim, in the second part of the paper, we estimate our model separately for each of the tobacco products, also splitting the past and future consumption of tobacco into the components of past and future consumption for a specific product, and past and future consumption of the other tobacco products, and estimating cross price elasticities among the products. The idea is that if consumers are addicted to tobacco and the nicotine it contains, then the mode in which it is consumed should matter little; on the other hand, if theirs is a habit, it is the repetition of the manner in which tobacco is consumed that needs to be repeated. The estimated coefficients would differ in the two cases, and our analysis (see Table 3) indicates strongly that past consumption of a given product is relatively more important than aggregate tobacco past consumption, suggesting habit rather than addiction.

Cigarettes were everywhere hand-made by skilled workers, typically females, up to the beginning of the 1880's. Subsequently, the establishment of mechanised production drove down radically the marginal cost of making them, while the cost structure of other tobacco products remained unaltered. The Italian Azienda dei Tabacchi jumped on the bandwagon relatively early, and in 189091 reported the purchase of two Bonsack cigarette machines, which had been patented in the US at the end of 1881, and used by Duke (which later became 
the American Tobacco Company) from 1884. ${ }^{4}$ Sales of cigarettes increased dramatically in Italy throughout the period we study, and the final question of the paper is the link between this increase and the mechanisation brought about by the Bonsack machines. We find that the structure of the demand function is largely unchanged during the period: from this we surmise that the Bonsack machines were not put in use in response to a change in demand, as is suggested to be the case in the US (see below, footnote 28), but were instead a business response to an exogenous change in technology.

The paper is organised as follows. Section 2 begins with the description of the consumers' behaviour, specifically the idea of rational addiction. This is estimated in Section 4, using the data presented in detail in Section 3. Section 5 studies the disaggregated dataset, estimating the demand for each product, and Section 6 concludes the paper.

\section{The theory: Consumers' behaviour and the rational addiction model.}

Our theoretical framework is the rational addiction model, due to Becker and Murphy (1988), and first estimated by Chaloupka (1991) using individual level data and by Becker et al. (1994) using data describing aggregate consumption through time in each of the US states. ${ }^{5}$ The essence of this model is that current utility from tobacco consumption, itself a balance of the positive "relaxation" effect and the negative impact on health, is affected by the "addictive stock" (Chaloupka 1991, p. 726) of past consumption: a higher addictive stock entails a lower enjoyment of a given quantity of current consumption. A rational

\footnotetext{
${ }^{4}$ Whether mechanisation of tobacco was an essential factor in Duke's business success (Chandler 1977, p. 382-391), or whether it was achieved by successful monopoly predatory practices (Hannah 2006) is tangential to the topic of this paper.

${ }^{5}$ An extensive survey of the rational addiction model is included in Chaloupka and Warner (2000). Critical appraisals of the model range from the view that serial correlation (Auld and Grootendorst 2004) and time inconsistent preferences (Gruber and Köszegi 2001) are indistinguishable from rational addiction. A more sweeping criticism is Rogeberg (2004). As Table 2 shows, the alternative framework of myopic addiction yields estimations of the price, income and education elasticities which are similar to those we derive with the rational addiction model.
} 
consumer projects this effect into the future and therefore adds to the utility balance of today's consumption the discounted present value of the effect on tomorrow addictive stock of a marginal change in today's consumption, and consequently on tomorrow's utility from consumption. The source of addiction, and hence the cause of this effect, can be physical addiction, habit formation or a combination of both. Lifetime utility maximisation implies therefore dependence of current consumption on future consumption and prices, as well of course as current prices and income: an exogenous change in future consumption, due, say, to higher future taxes, changes the future marginal utility of consumption, and hence, via the addictive stock link, the current marginal utility of consumption. Current consumption adjusts in responses to this change.

Applying these ideas, Becker et al. (1994, p. 398) and Baltagi and Griffin (2001, p. 450) estimate the following equation:

$$
C_{i, t}=\alpha_{0}+\alpha_{1} C_{i, t-1}+\alpha_{2} C_{i, t+1}+\alpha_{3} P_{i, t}+\alpha_{4} Y_{i, t}+\alpha_{5} P_{i, t}^{N}+\varepsilon_{i t},
$$

using panels from US states which records consumption of cigarettes from 1955. In the above, $C_{t}$ is consumption in period $t$, and $P_{t}$ and $Y_{t}$ are the price and the income, respectively, in period $t . P_{t}^{N}$ is the average price of tobacco in neighbouring states, to account for the possibility of smuggling, whether casual or organised.

Becker et al. (1994) derive (1) from a standard lifetime utility maximisation problem, where a rational consumer maximises the discounted present value of the sum of future utility, which in each period is given by a quadratic utility function, with arguments tobacco consumption and consumption of all other goods. The consumer can save and borrow (at the same rate) against future income, and is therefore subject to a lifetime budget constraint. The derivation of (1) is standard and we do not repeat it here (see Becker et al. 1994, p. 398 and Baltagi and Griffin 2001, p. 450, for details).

We adapt (1) to take into account the nature of our available data, discussed in detail below, in Section 3. We do not include $P^{N}$, since the price of each product was established by royal decree and had to be uniform across the entire national territory. We also augment the specification used by Becker et al. (1994) and Baltagi and Griffin (2001) to include a proxy for education, nowadays another recognised correlate of smoking (Giskes et al. 2005, Gilman et al. 2008). Specifically, we estimate the following variant of the rational 
addiction model:

$$
C_{i, t}=\alpha_{0}+\alpha_{1} C_{i, t-1}+\alpha_{2} C_{i, t+1}+\alpha_{3} P_{i, t}+\alpha_{4} T_{i, t}+\alpha_{5} I_{i, t}+\varepsilon_{t}
$$

where $C_{i, t}$ is the $\log$ of the per capita amount of tobacco consumed in year $t, t=1871, \ldots, 1913$, in province $i, i=1, \ldots, 69$, measured in kilograms. $P_{i, t}$ is the log of the average price of tobacco paid by consumers in year $t$, in province $i$, measured in 1911 lire. $T_{i, t}$ and $I_{i, t}$ are the log of the per capita proxy of income, measured in 1911 lire, and of the population education level in province $i$ in year $t$. Using logs has the advantage that the coefficients are short-run elasticities, giving immediately the percentage change in quantity consumed that would follow a small percentage change in price or income. ${ }^{6}$ As in Becker et al. (1994), the error term $\varepsilon_{i t}$ is a two-way error-component:

$$
\varepsilon_{i t}=\mu_{t}+\nu_{i}+u_{i t}, \quad t=1, \ldots, T, \quad i=1, \ldots, I .
$$

In (3), the $\nu_{i}$ are the time-invariant province-specific effects, the $\mu_{t}$ are the province-invariant time-specific effects, and $u_{i t}$ is a white noise, normally and independently distributed across provinces and periods. The methodology in Becker et al. (1994) also lets us calculate the long run elasticities and the implied intertemporal rate of substitution. The former are the percentage changes in consumption that would follow a permanent change in price or income, that is, after the consumers have adjusted the quantity to their desired long term value, so that $C_{i, t}=C_{i, t-1}=C_{i, t+1}$. The long run price elasticity is calculated as

$$
\frac{\alpha_{3}}{1-\alpha_{1}-\alpha_{2}} \text {. }
$$

Analogously for the long run income elasticity, given by

$$
\frac{\alpha_{4}}{1-\alpha_{1}-\alpha_{2}} \text {. }
$$

The intertemporal rate of substitution is the rate at which future utility is compared to current one: other things equal, it gives the amount of additional future consumption that is necessary to offer a consumer to induce him to delay current consumption by one period. It is calculated as

$$
\frac{\alpha_{1}}{\alpha_{2}}-1
$$

\footnotetext{
${ }^{6}$ This is a departure from the earlier literature which begun with Becker et al. (1994), and is in line with several of more recent contributions (e.g. Gospodinov and Irvine 2005).
} 


\section{The facts of the case: The new tobacco dataset}

We estimate (2) using a very rich dataset which we have constructed from the annual budget reports of the companies entrusted to manage the tobacco industry. These budget reports collect annual sales, in values and in physical quantities, of four groups of tobacco products in 69 Italian provinces from 1871 to 1913.

The richness of the dataset is due partly to the special institutional details of the Italian tobacco industry of the time. ${ }^{7}$ In the initial part of the period (1871-1883), the entire national domestic production and the distribution to retailers of all tobacco products, whether domestically produced or imported, was handed over to a private company, closely inspected by the government, the Società Anonima per la Regìa Cointeressata dei Tabacchi (Regìa hereafter), a syndicate of European financial organisations; from 1884, the tobacco industry was managed by the state owned Azienda dei Tabacchi The Regìa leased every government owned plant and equipment, and was awarded the monopoly franchise for the manufacture and distribution of all tobacco related products in the kingdom. Revenue from tobacco totted up to around $12 \%$ of the total government revenues, and so was very important for the young Italian state. Since payment was profit related, the contract required the Regìa to keep a very accurate accounting record. ${ }^{8}$ The primary sources report provincial ${ }^{9}$ sales

${ }^{7}$ An exhaustive historical long-term account of the rise and fall of the State monopoly in Italy from 1861 to 1997 is Vetritto 2005, and a detailed description of the sources on tobacco used here is Ciccarelli (2012). After Manera's early work (1963), tobacco consumption in Italy has been analysed, for the second half of the 20-th century by Jones and Giannoni-Mazzi (1996), Tiezzi (2005), Aristei and Pieroni (2008), and Pierani and Tiezzi (2009) among others.

${ }^{8}$ We note an accounting change in the financial year 1884. Available data for the years 1871 to 1883 runs from January to December; subsequently there is financial data for the January-June semester of 1884, and, from then on, the reporting period shifts to July-June. The customary manner (see for instance Fenoaltea 1986, p. 8) to deal with this quirk is to split in half the values of each reported year and construct the value for the calendar year by adding up the two halves obtained from two subsequent reported years: so, for example, the values for year 1900 are obtained by adding half of the year 1899 and half of the year 1900 .

${ }^{9}$ Data for Sicily, which had seven provinces, is missing for the years before 1877. While of course Sicilians did smoke in those years, their purchases were not recorded by the Regìa, as the monopoly was extended to Sicily only in 1877 . To sum up, our unbalanced panel includes 62 provinces in the years 1871-1876 and all 69 Italian provinces in the years 1877-1913. 
from warehouses, which were evenly distributed across the country, to authorised retailers both in weight (kilograms) and in values (lire), for the several dozens different products available for sale. ${ }^{10}$ These can be aggregated into four main categories, distinct by the manner of consumption: snuff (polveri), fine-cut tobacco (trinciato), cigars (sigari), and cigarettes (spagnolette). We convert sales of cigars and cigarettes, reported in numbers, into notional kilograms using the equivalence scales legally mandated by the government (Regio Decreto 171 of 21 April 1901), whereby one kilogram of cut tobacco or snuff equal 200 cigars and 1000 cigarettes. The mark-up applied by retailers was the same for each product, and regulated by royal decree.

Consumption in a period might differ from sales in the same period because of smuggling and because of hoarding. Despite the relative weakness of the young Italian state in enforcing its laws, some historical evidence (eg. Luciani 2006, pp. 18 ff.) suggests that in the years between unification and World War I, smuggling was in fact a limited problem. The Regia itself reports that in the years 1873-1879 a total of about 90,000 kilograms of leaves and 240,000 kilograms of manufactured tobacco were seized in the country. While low seizure might simply reflect incompetence or corruption of the relevant policing agency, this amount is only approximately $0.02 \%$ of the quantity sold in the same period. A second potential source of discrepancy between sales and consumption might be hoarding by consumers and retailers in anticipation of a price increase. The government was aware of this possibility, which it minimised by introducing the price changes with a Regio Decreto (a king's executive order). These orders came into force the moment they were announced, with Parliamentary ratification required within a set time, and hence did not allow prior Parliamentary discussion to alert consumers of a possible increase. ${ }^{11}$

\footnotetext{
${ }^{10}$ Italian consumers in the period considered could choose around 100 different tobacco products. Quantities and prices for each of all these products are available up to the fiscal year 1888-89, four years after the expiration of the contract, in 1884: subsequently, the monopoly was fully managed by the State. Ciccarelli et al. (2012) use this detailed information to investigate the profit maximising behaviour of the Regìa. After 1889, the dataset contains the complete series, for each province, of the total sales, in weight and in values, of the four broad groups of tobacco products: less detailed, but adequate for our purpose.

${ }^{11}$ In the words of Agostino Magliani, the Finance Minister himself: "consumers, with advanced warning of a price increase, would detract enormous amounts of tobacco from the new tariff" (Atti Parlamentari 1878, p. 2).
} 
Table 1: Descriptive statistics, $1871-1913^{a}$

\begin{tabular}{llrrrr}
\hline \multirow{2}{*}{ Consumption $^{b}$} & & mean & s.dv. & min & $\max$ \\
\cline { 2 - 6 } & snuff & .16 & .13 & .01 & .74 \\
& fine-cut tobacco & .34 & .25 & .11 & 1.59 \\
& cigars & .29 & .14 & .04 & 1.33 \\
& cigarettes & .03 & .05 & .00 & .47 \\
& total & .81 & .40 & .22 & 2.38 \\
Price $^{c}$ & snuff & 7.58 & 2.60 & 3.20 & 14.70 \\
& fine-cut tobacco & 8.33 & 2.33 & 3.47 & 14.32 \\
& cigars & 17.05 & 4.33 & 7.55 & 22.08 \\
& cigarettes & 30.53 & 5.64 & 20.16 & 52.73 \\
Business $^{*}$ Tax $^{d}{ }^{d}$ & total & 12.23 & 4.10 & 4.17 & 23.09 \\
& & 5.67 & 3.45 & 1.62 & 33.74 \\
& & .62 & .18 & .16 & .92 \\
\hline
\end{tabular}

${ }^{a}$ Descriptive statistics on tobacco are based on annual data relative to 69 provinces for the years 1877-1913; figures for the early years (1871-1876) are based on a sub-sample not including the seven Sicilian provinces. The resulting total number of observations is thus equal to 2925; descriptive statistics on business tax and illiteracy are based on (43 years $\times$ 69 provinces) $=2967$ observations. ${ }^{b}$ per-capita consumption (kilograms); ${ }^{c}$ real prices (lire per kilogram); ${ }^{d}$ per-capita business tax in real prices (lire); ${ }^{e}$ percentage of illiterates over total population. Source: see text.

Provincial consumption data is measured on a per-capita basis, with population data derived from the population censuses. ${ }^{12}$ We use data for the population over 15, though little changes in any estimation if we use the entire population instead. The values for $C_{i, t}$ are obtained from this data by adding up the quantities of each product: they are summarised in the first part of Table 1 , which collects descriptive statistics. On average 0.8 kilograms of tobacco per-year were consumed by each member of the population over 15, with snuff accounting for about one fifth and the rest approximately shared between cut

\footnotetext{
${ }^{12}$ For the non-census years, we do not use the annual population figures reported in the main sources on tobacco, as they appear seriously flawed, with large unjustified annual changes. A linear interpolation of the figures for the census years (1871, 1881, 1901 and 1911) is preferable.
} 


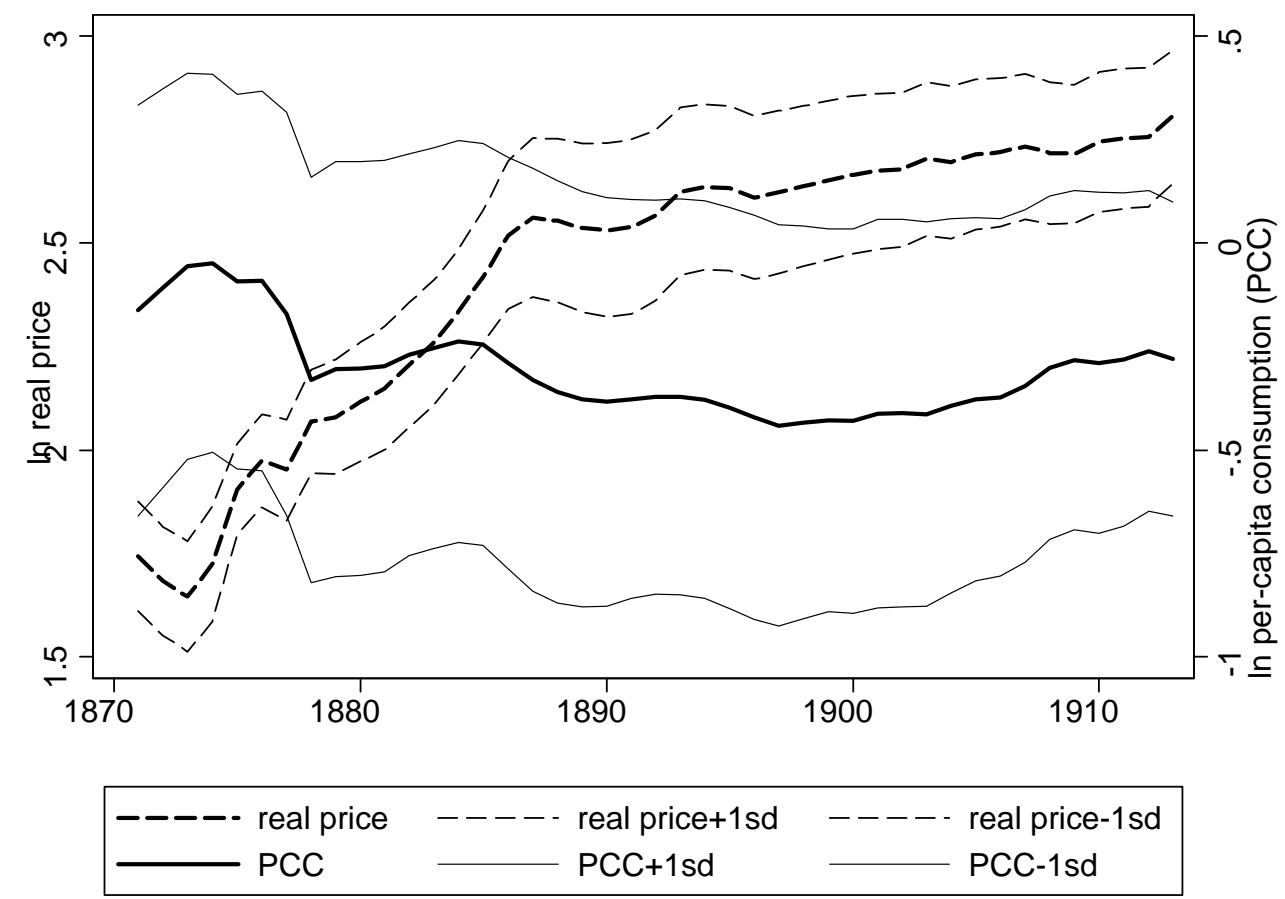

Figure 1: Total Tobacco: per capita consumption and average price, 1871-1913 (mean of logarithm.) Source: see text.

tobacco and cigars, with cigarettes negligible except towards the end of the period.

The nominal values of $P_{i, t}$ are obtained by dividing the monetary value of the sales of each product by the quantity sold in each year and in each province; we adjust all nominal monetary values into real terms using the cost of living index proposed in Fenoaltea $(2002)^{13}$, and convert all monetary values into 1911 lire. Figure 1 gives a picture of the aggregate trends in price and quantities. It shows the national average of real price and per-capita consumption, measured on the left and right axis, respectively. Per-capita consumption declined slowly

\footnotetext{
${ }^{13}$ The "official" cost of living index is given in Istat (1958, p. 172). This has two drawbacks. The first is that it includes the price of bread, but not of flour, and thus neglects inferior grains. The second is that it assigns (or it appears to assign, as full documentation is not available) very low weights to fundamental basic goods, such as bread. The Istat index may thus be appropriate for the better-off, but not for a rural economy, such as Italy at the time. See Fenoaltea (2002) pp. 31-33, for further details of the index he constructs.
} 
in the long-run, though an upward trend appears to start in the mid 1890s at the eve of the belle époque, in concomitance with the reduction in the rate of price increases and with the introduction of the Bonsack machine, discussed in Section 5 below. Notice also how, in the short run, quantity responds sharply to price reforms: the main ones took place in 1875, 1878, 1885 and 1910, with smaller adjustments in other years. For both variables, Figure 1 shows the range of plus and minus one standard deviation. Spatial variation of per-capita consumption was quite ample, and naturally, price geographical variability was much lower, since the price of each product was, in any given moment in time, constant across the Kingdom, and provincial differences in prices were simply a consequence of different patterns of consumption: some provinces preferred more expensive products, and so the average price calculated there is higher. This of course implies that we are using "unit values", which are partly a consequence of consumers' preferences for quality, rather than prices, which are exogenous (Deaton 1997, pp. 288 ff.): with our data, just as for the other aggregate tobacco dataset used by the existing literature, this is a consequence of need to average the prices of several different products.

Demand for tobacco products depends of course on disposable income too. Yearly provincial estimates of disposable income do not exist. Obtaining reliable proxies is a hard enough task at the national level, let alone at the more disaggregated provincial level. In this paper we therefore resort to proxying provincial disposable income with an appropriate measure of tax receipts. We choose as proxy the sum of the three main components of the broad category defined "Business tax" (tassa sugli affari) in the ministry accounts. The state budget had at the time three main categories of taxes, "Direct taxes", "Consumption taxes", and "Business taxes". The first were essentially wealth taxes, and therefore had a very narrow basis, with the number of taxpayers limited to a subset of the wealthiest households. Consumption taxes were likely skewed in the opposite direction: they were levied on specific goods, such as grappa, beer, chicory, sugar, gunpowder, and flour, the much hated tassa sul macinato. Business taxes had instead a relative wide and representative basis, and they were one form of taxation which in the immediate years after unification was sufficiently homogenous across the country to give meaning to comparisons of tax bases and tax receipts between distant provinces (Plebano 1899, Boria 2008). The amount of business tax raised in each province is therefore 


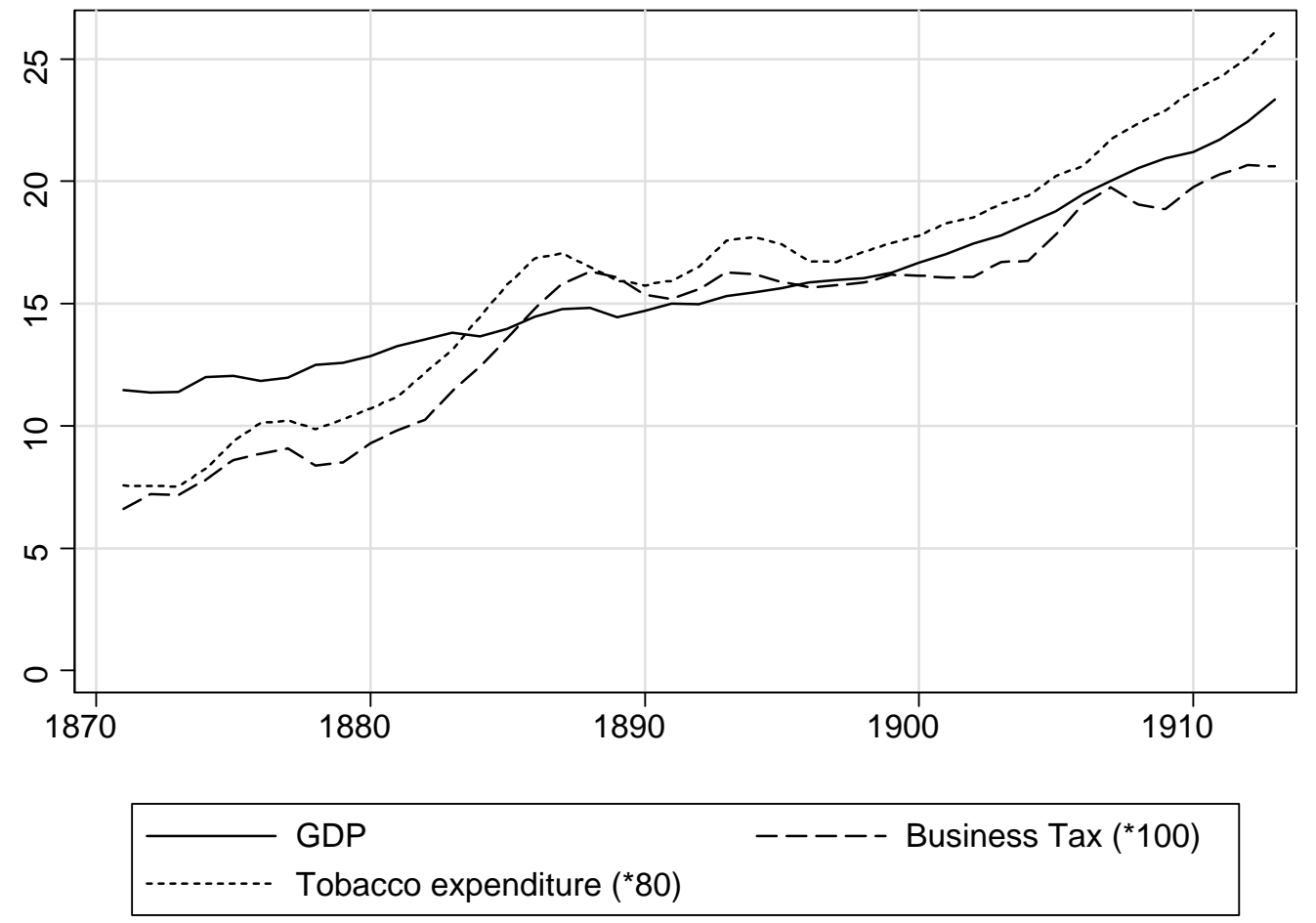

Figure 2: GDP, Business Tax, and Expenditure on Tobacco 1871-1913 (billion lire at 1911 prices). Source: see text.

one of the best available proxies of economic activity at province level (inclusion of fixed effects accounts for special circumstances affecting only some provinces, for examples, those that had a major port). ${ }^{14}$ In detail, our proxy, which accounts for approximately $15 \%$ of total government receipts, and about $1 \%$ of GDP, comprises taxes on transfers of property and other contracts for real assets, such as lets and mortgages, which required transcription onto the Land Registry, and on transfers of financial assets such stocks and bonds, it also includes all required stamp duties on such disparate items as court acts and petitions, IOUs, cheques, train, tram and theatre tickets, playing cards, insurance and so on.

Nowadays, the standard proxy for disposable income is GDP. The corre-

\footnotetext{
${ }^{14}$ We note that Mortara (1913) also uses the business tax to construct his measure of regional development index.
} 


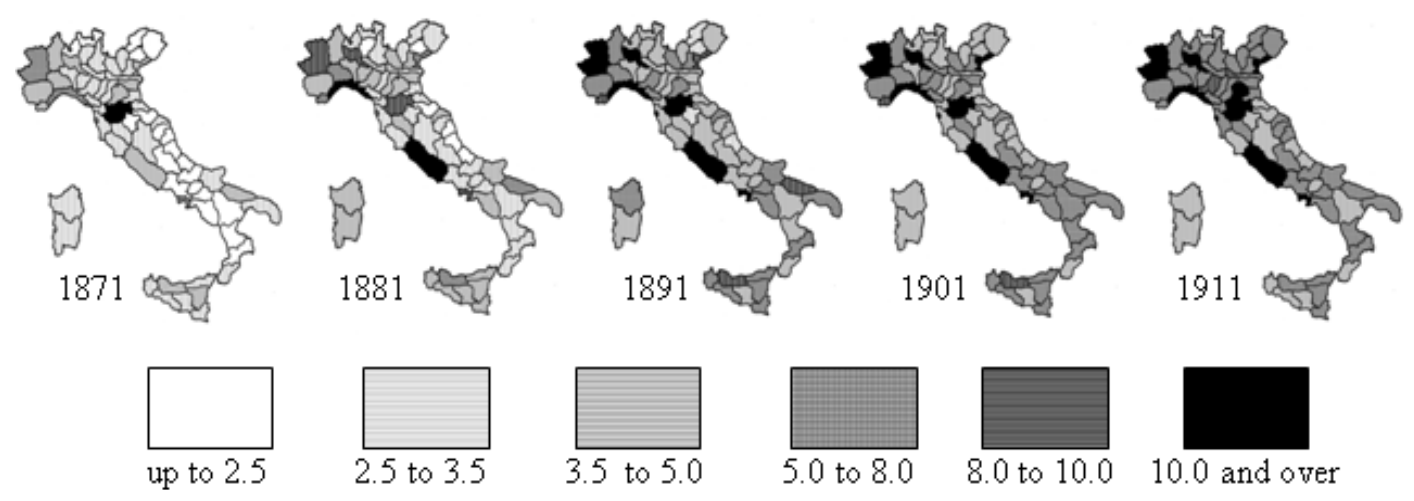

Figure 3: Per-capita Business Tax in Italian Provinces (1911 lire). Source: see text.

lation between the national real GDP (estimated in Fenoaltea 2005) and the national total take of the real Business tax in the period 1871-1913 is 0.92. This lends support to the use of Business taxes as a proxy for households' disposable income. Figure 2 shows the time trend of these two variables; for comparison, it also includes real expenditure on tobacco. Also encouragingly, the match between GDP and business tax is good at "local" level too. While provincial GDP is not available for any year, Brunetti et al. (2011, p. 428) calculate estimates of GDP for 16 regions for the years 1871, 1891 and 1911: since each region contains a subset of the provinces, we can calculate our proxy in each region for the selected years. We find that the correlation between these values and our regional total of the business tax take is $0.90,0.84$, and 0.92 in the three census years. Figure 3 shows the provincial distribution of revenues from these taxes. Note the long-known ${ }^{15}$ substantial geographical imbalances in the distribution of income in Italy in the period. Figure 2 also illustrates the evolution over time of the real expenditure on manufactured tobacco. It correlates strongly with our business tax variable (the correlation coefficient is $0.98)$.

Finally, our proxy for education. We use the census reports of the percentage of the population who are illiterate, and interpolate this for the non-census

${ }^{15}$ Clough and Livi (1956) and Eckaus (1961) among the earliest to point it out; Felice (2011), p. 931 and Brunetti et al. (2011), p. 223, and Ciccarelli and Fenoaltea (2013) give a summary of the more recent debate. 
years. Alternative measures, such as the illiteracy rate for the population over a certain age, or of one sex only are all highly correlated with our measure. As with income, there is considerable inequality across the country (see Figure 4). ${ }^{16}$ Note, however, that at -0.37 , the negative correlation between income and illiteracy is relatively low.

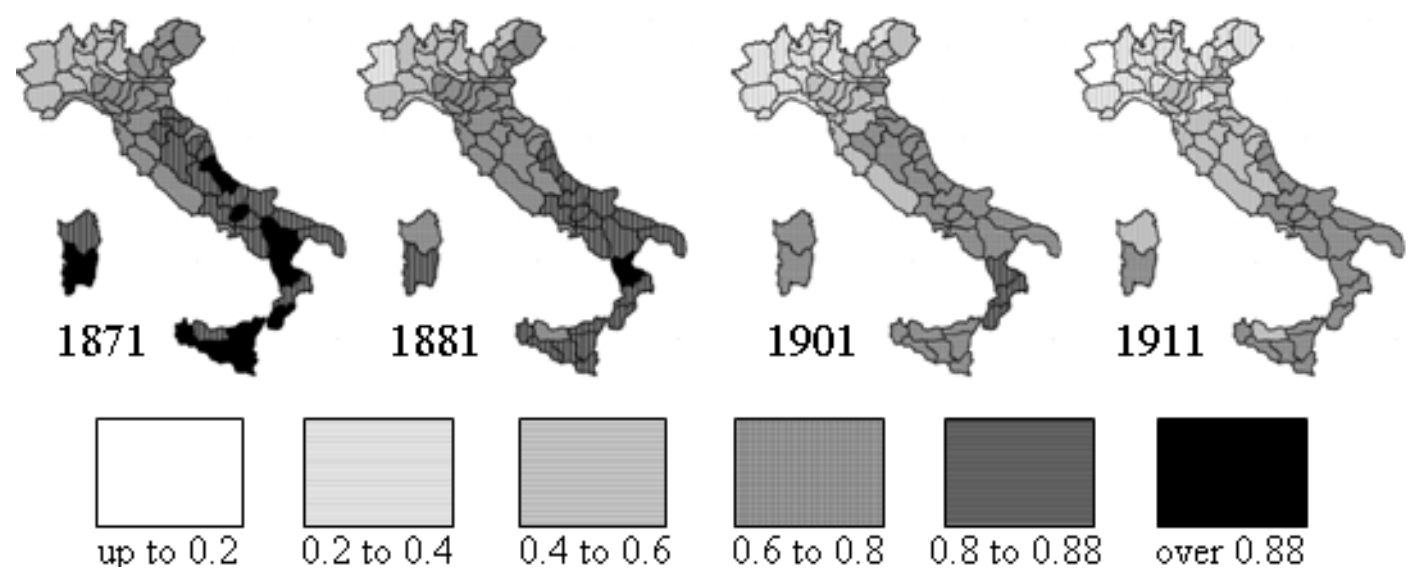

Figure 4: Illiteracy Rate in the Italian Provinces in the Census years. Source: see text.

\section{Marrying the theory and the facts: The em- pirical evidence}

Just as with the theory model we refer to the existing literature for a discussion of the possible alternative econometric approaches; in particular, Baltagi and Griffin (2001), Baltagi et al. (2000) provide a full account of the appropriate econometric techniques for the rational addiction model.

Our econometric results are shown in Table 2: each column reports the estimation of an alternative econometric specification for equation (2). The first column, headed GMM1, is our preferred specification. As in Baltagi's papers, (2) is estimated using a GMM system estimator (Arellano and Bover 1995), with the current and past values of prices and the present and past values of

\footnotetext{
${ }^{16}$ Felice (2012) notes that primary and secondary enrolment rates at the regional level also point to high education inequality across the country.
} 
Table 2: Models of addiction: alternative estimates, $1871-1913^{a}$

\begin{tabular}{|c|c|c|c|c|}
\hline & RATIOI & $\overline{\mathrm{AL} \mathrm{ADI}}$ & ICTION & \\
\hline & GMM1 & GMM2 & FE2SLS & MYOPIC \\
\hline$C_{t-1}$ & $0.525^{*}$ & $0.520 *$ & $0.129^{*}$ & $0.782^{*}$ \\
\hline & $(0.011)$ & $(0.010)$ & $(0.060)$ & $(0.028)$ \\
\hline$C_{t+1}$ & $0.407^{*}$ & 0.425 * & $0.664^{*}$ & - \\
\hline & $(0.022)$ & $(0.018)$ & $(0.085)$ & - \\
\hline$P_{t}$ & $-0.189^{*}$ & $-0.163^{*}$ & $-0.148^{*}$ & $-0.459^{*}$ \\
\hline & $(0.033)$ & $(0.027)$ & $(0.034)$ & $(0.046)$ \\
\hline$T_{t}$ & $0.088 *$ & $0.075^{*}$ & $0.089 *$ & $0.213^{*}$ \\
\hline & $(0.019)$ & $(0.015)$ & $(0.010)$ & $(0.031)$ \\
\hline$I_{t}$ & $0.093 *$ & $0.085 *$ & 0.030 & $0.147^{*}$ \\
\hline & $(0.028)$ & $(0.025)$ & $(0.023)$ & $(0.062)$ \\
\hline derive & & & & \\
\hline$r$ & $0.289^{*}$ & $0.224^{*}$ & $-0.805^{*}$ & - \\
\hline & $(0.086)$ & $(0.068)$ & $(0.111)$ & 一 \\
\hline$L R \mathrm{P}$ & $-2.764^{*}$ & $-2.961^{*}$ & $-0.712^{*}$ & -2.099 \\
\hline & $(0.510)$ & $(0.549)$ & $(0.036)$ & $(0.287)$ \\
\hline$L R Y$ & $1.289^{*}$ & $1.362^{*}$ & $0.429^{*}$ & 0.974 \\
\hline & $(0.229)$ & $(0.246)$ & $(0.080)$ & $(0.164)$ \\
\hline
\end{tabular}

a The dependent variable is the total per capita consumption of tobacco products. The dependent variables are explained in the text, after equation (2). Numbers in parentheses denote absolute values of asymptotic standard errors. The superscript $*$ indicates that the estimated coefficient is significantly different at the $5 \%$ significance level from 0 . All regressions include a time trend. Current and past value of prices and taxes used as instruments in columns GMM1, FE2SLS and MYOPIC; future prices also used as instruments in GMM2. Source: see text.

our GDP proxy as instruments for past and future consumption. In general, the GMM estimators, both the Arellano-Bond and the system versions, offer an increase in efficiency relative to the approach to handle dynamic models for panel data pioneered by Anderson and Hsiao (1981). The latter takes the first-differences of the dynamic model and uses the second lag of the dependent variable as instrument for its first differences; instead, GMM estimators, which are designed to handle effectively the "large- $N$-small- $T$ " framework of- 
ten encountered in applied micro research, exploit many more orthogonality conditions, one for each time period and one for each lag available, resulting in a number of instruments that grows quadratically with the length of the panel. The obvious drawback of this is that in a moderately long panel, such as our 43-year long dataset, the number of instruments becomes very large, which potentially introduces bias in the estimation. ${ }^{17}$ We deal with this problem in two ways: firstly, we "collapse the instrument sets" using the automatic procedure provided by Roodman (2009), which assumes that the orthogonality conditions need not be valid for any time period but only for each lag, implying that the number of instruments increases linearly with time. Secondly, we use additional "external" instruments for tobacco consumption, namely the current and past values of prices and our income proxy.

Within the GMM class, system GMM uses the moment conditions on equations in levels in addition to the moment conditions on the first-difference equation, and, in our case, it performs better than the Arellano-Bond estimator. ${ }^{18}$ The estimated parameters in our preferred specification, column GMM1, are significant and display the expected signs; the positive income coefficient suggest that tobacco was a normal good, which is plausible given the lack of health awareness in Italy at the time. The high value of forward consumption suggests rational addiction. The range of the short run price elasticity is from -0.15 to -0.46 , which is somewhat lower, but clearly in the same ballpark as the estimates found in the literature analysing tobacco consumption in more recent periods and for different countries. The calculated parameters, reported in the second part of the table, are also plausible. The long term price elasticity, $L R P$ in the table, far exceeds the short run elasticity, and the intertemporal rate of substitution, $r$, is in its reasonable range. The positive long-run income

\footnotetext{
${ }^{17}$ An intuitive explanation of the problem is as follows. Two-stages least squares (2SLS) are members of the GMM family. In a standard 2SLS framework, if the number of instruments equals the number of observations, then the regression run in the first stage returns, by construction, an $R^{2}$ equal to 1 . As a consequence the second-stage regression returns the very same (biased) OLS estimates that called for the 2SLS approach in the first place. See Roodman (2009), pp. 148-149 for the technical details.

${ }^{18}$ To check that the instruments we use are appropriate, we executed the standard Sargan over-identification test (whose statistics is distributed as a $\chi^{2}$ with one degree of freedom). The null is that the over-identification restrictions are valid. We fail to reject it (i.e. we obtain high p-values) and this allows us to conclude that our instruments set is appropriate.
} 
elasticity is positive, further confirming that tobacco was a normal good at the time. The coefficient for $I_{t}$, the rate of illiteracy, suggests that more educated provinces consumed less tobacco: other things equal, the less educated consume more tobacco. In contrast to the coefficient for income, this is similar to the present-day finding of negative correlation between education and smoking. ${ }^{19}$

Baltagi and Griffin (2001, p. 450) note that in the original Becker et al. (1994) contribution the "support for the rational addiction [becomes] weak when [future prices are] excluded from the set of instruments". They therefore reestimate their model with a new set of regressions which also includes future tobacco price in the set of instruments. We follow their technique in the second column of Table 2, headed GMM2. These two specifications give very similar results and so the issue of whether or not future prices should be included is less central in the present case. Similarity between the results of the first two columns also indicates robustness in our analysis. In addition, again following Becker et al. (1994), we report, in column 3, the result of the fixed effects 2SLS used in their paper, even though it is known to be biased for finite $T$. In this case also, some robustness in the estimates is indicated by the similarity of this set of coefficients and those in the first two columns, though the implied intertemporal rate of substitution turns to negative. The fourth column reports the estimation of the myopic model, obtained using the same technique as in column GMM1, with past prices used as instruments. Signs and magnitudes of price and income elasticities are similar, though, obviously, not the addiction coefficient of past consumption $C_{i, t-1}$. We take this as a further encouraging suggestion of robustness in our results.

\section{On the structure of demand and the cause of addiction}

In the decades following the unification of their country, Italians consumed tobacco, we concluded in the previous section, partly because they had consumed

\footnotetext{
${ }^{19}$ The Sargan test for overidentification does not reject the null, suggesting valid instruments. The Arellano-Bond tests for first and second order serial-correlation yield the expected results: the null for absence of first order serial correlation is rejected, the null of presence of second order serial correlation is rejected.
} 
it before and expected to consume it in the future. The persistence of their consumption, in other words, was not simply due to stability of preferences. This comes as no surprise of course, as smoking nowadays is well-known to be addictive.

As mentioned in the introduction, the medical literature distinguishes between physical dependence and the habit created by the repetition of familiar gestures and behaviours involved in consumption. Given the rather different nature of consumption in the four products, and the similarity in their nicotine addiction properties, ${ }^{20}$ one possible way to disentangle the two potential sources of addiction would be to ascertain whether the cause of persistence in the consumption of a specific product is past consumption of tobacco and the nicotine it contains per se, or rather the past consumption of that specific product. If the former, then one would conclude that addiction is to nicotine, however consumed; if the latter, what becomes "necessary" to the consumer is the behaviour associated with consumption, rather than the nicotine itself. A second argument can be made with respect to own and cross price elasticity. This measures how substitutable the various products are with one another. A low rate of substitutability between two products indicates strong "loyalty" to a given product: consumers are not swayed by changes in the relative prices of the products. Conversely, if, after adjusting for size, the coefficients for "own" and "other products" past and future consumption are similar, and the "own" and "cross" price elasticities are similar in absolute value, then we would conclude that consumers are more interested in tobacco than the manner of its consumption. $^{21}$

\footnotetext{
${ }^{20}$ We do not have tests for the products available in Italy at the time, but current medical research (Richter and Spierto 2003, Richter et al. 2008, or the earlier survey by Benowitz, 1988) suggest that smokeless tobacco is as likely to determine addiction to nicotine (and to other substances) as other currently used forms of smoking tobacco.

${ }^{21}$ A hypothetical example illustrates this point. Imagine that we are studying smokers' behaviour in a European country. We think that smokers are of two types, those who are addicted to smoking, and the poseurs, who smoke to project an image; the better to advice policy makers on how to design an anti-smoking campaign, we would like to know the relative size of the two groups of smokers. To continue our example, imagine that the "poseurs" are in turn further divided into two groups, those who like to project the tough image of a rough American cowboy, associated with brand M, sold in a red and white package, and those who wish to be seen as French type intellectuals, which they think they can by smoking brand $\mathrm{G}$, rolled in yellow paper and sold in a light blue package. The addicted smokers have no
} 
To proceed, we simply disaggregate the dataset back into the four components, snuff, cut tobacco, cigars, and cigarettes, we aggregated in Section 4 and repeat the calculations of that section for each product: we regress the quantity of each product consumed in period $t$, in province $i$, against lagged and forward consumption of that product, just as in (2), but also against the lagged and forward consumption of the total amount of the other products consumed. ${ }^{22}$ Similarly for prices, we include the current price of each product and the price of the other tobacco products, obtained by dividing the sum of the sales of the three remaining products by the sum of their quantities.

preference for a brand: they choose depending on prices; their current and future consumption is affected by past consumption, of whichever brand they happened to have consumed in the past and expect to consume in the future. If all tobacco consumers were addicted smokers, then the aggregate demand for each brand would exhibit strong substitutability between brands (the coefficient for brand $M$ would have approximately the same absolute value and the opposite sign as the coefficient for brand G), and the current consumption of each brand would be similarly affected by past and future consumption of the two brands (the coefficients for past and future consumption of brand $\mathrm{M}$ would have approximately the same values as the corresponding coefficients for brand $\mathrm{G}$ ).

Not so for image conscious smokers. The cowboy type finds brand $G$ useless to project his desired image, and won't be swayed into buying brand G by a price reduction. Similarly for brand M: French intellectual types would not touch it with a barge pole, no matter how cheap it is. The price substitution coefficient is 0 for these types. Also 0 is the addiction coefficient for the other brand. To sustain their image, they need the specific brand associated to that image to do so, so an increase in past consumption of the "wrong" brand (for whatever reason it happened) has no effect on the current consumption of their desired brand: econometrically, both the cross price elasticity and the "other products past and future consumption" elasticities would give estimates close to 0 .

So, if we found that the consumption of brands $\mathrm{G}$ (brand $\mathrm{F}$ ) is increased little by a price increase in brand F (in brand G), and is increased little by an increase in the past or future consumption of brand $\mathrm{F}$ (of brand $\mathrm{G}$ ), where little means relative to the own effects, then we would conclude that most consumers are poseurs: they care about the brand, not the smoking. Vice versa, large cross price substitutability coefficients and large cross brand addiction coefficients suggest most consumers are physically addicted.

${ }^{22}$ Not the total amount used in (2), because that includes the consumption of the product being considered. 
Formally, we estimate the following four equations:

$$
\begin{aligned}
C_{i, t}^{J}= & \beta_{0}^{J}+\beta_{1}^{J} C_{i, t-1}^{J}+\beta_{2}^{J} C_{i, t-1}^{J}+\beta_{1}^{N J} \sum_{K \neq J} C_{i, t-1}^{K}+\beta_{2}^{N J} \sum_{K \neq J} C_{i, t+1}^{K} \\
& +\beta_{3}^{J} P_{i, t}^{J}+\beta_{3}^{N J} P_{i, t}^{N J}+\beta_{4}^{J} T_{i, t}+\beta_{5}^{J} I_{i, t}+\varepsilon_{i t}^{J}, \quad J=F, P, C, S
\end{aligned}
$$

In (4) the coefficient $\beta_{h}^{J}$ correspond to the coefficients $\alpha_{h}$ in (2), $h=$ $0,1, \ldots, 5$. These are, respectively, a constant, the coefficient of past and forward consumption of product $J$, the price of product $J$, the income proxy and the education proxy. The additional coefficients are $\beta_{1}^{N J}, \beta_{2}^{N J}$, and $\beta_{3}^{N J}$. These are the regression coefficients of lagged and forward quantities of "product not $J$ ", and the price of "product not $J$ ". The first two separate the effect of past and forward consumption of different types of products on current consumption: in (2) they are constrained to equal the corresponding "own" coefficient: $\beta_{1}^{N J}=\beta_{1}^{J}$ and $\beta_{2}^{N J}=\beta_{2}^{J}$. Here instead past consumption of each type of tobacco is allowed to be influenced differently by the past or future consumption of different types of tobacco. Similarly for price: consumers may substitute away from one type of tobacco to a different type, depending on prices, and $\beta_{3}^{N J}$ captures the cross price effects. ${ }^{23}$

Figures 5 and 6 give snapshots of the data we use, for quantities and prices. Figure 5 shows the long-term per capita consumption of snuff, cut-tobacco, cigars, and cigarettes in selected years from 1871 to 1911. Snuff, shown in the top row of maps, was rather more diffused in 1871 with a clear predominance in the North-East. Per head consumption of cut tobacco is much more variable than that of snuff and of cigars and cigarettes combined. In some provinces (Rovigo, Ferrara, and Livorno among them) consumption of snuff was very high. Cigars and cigarettes become more diffuse as time goes by, the latter starting from a very low level, with snuff and cut-tobacco declining slowly. Cigars are

\footnotetext{
${ }^{23}$ There is a small recent literature studying the interaction of two or more addictive products (Andersson et al. 2006, Lee 2007, Pierani and Tiezzi 2009). With separate goods, such as alcohol and smoking, the cross price elasticity coefficient has the same interpretation as that between, say snuff and cut tobacco; but, clearly, the question of the disentangling the source of addiction, whether physical or habit, does not make sense in the context of products like alcohol and tobacco, given the different substance considered to cause addiction. A recent comparative study for a number of European countries does estimate cross price elasticities, for the countries which have data for more than one product (Netherlands, Finland, Sweden), but does not separate past and future consumption into its components (Nguyen et al. 2012).
} 

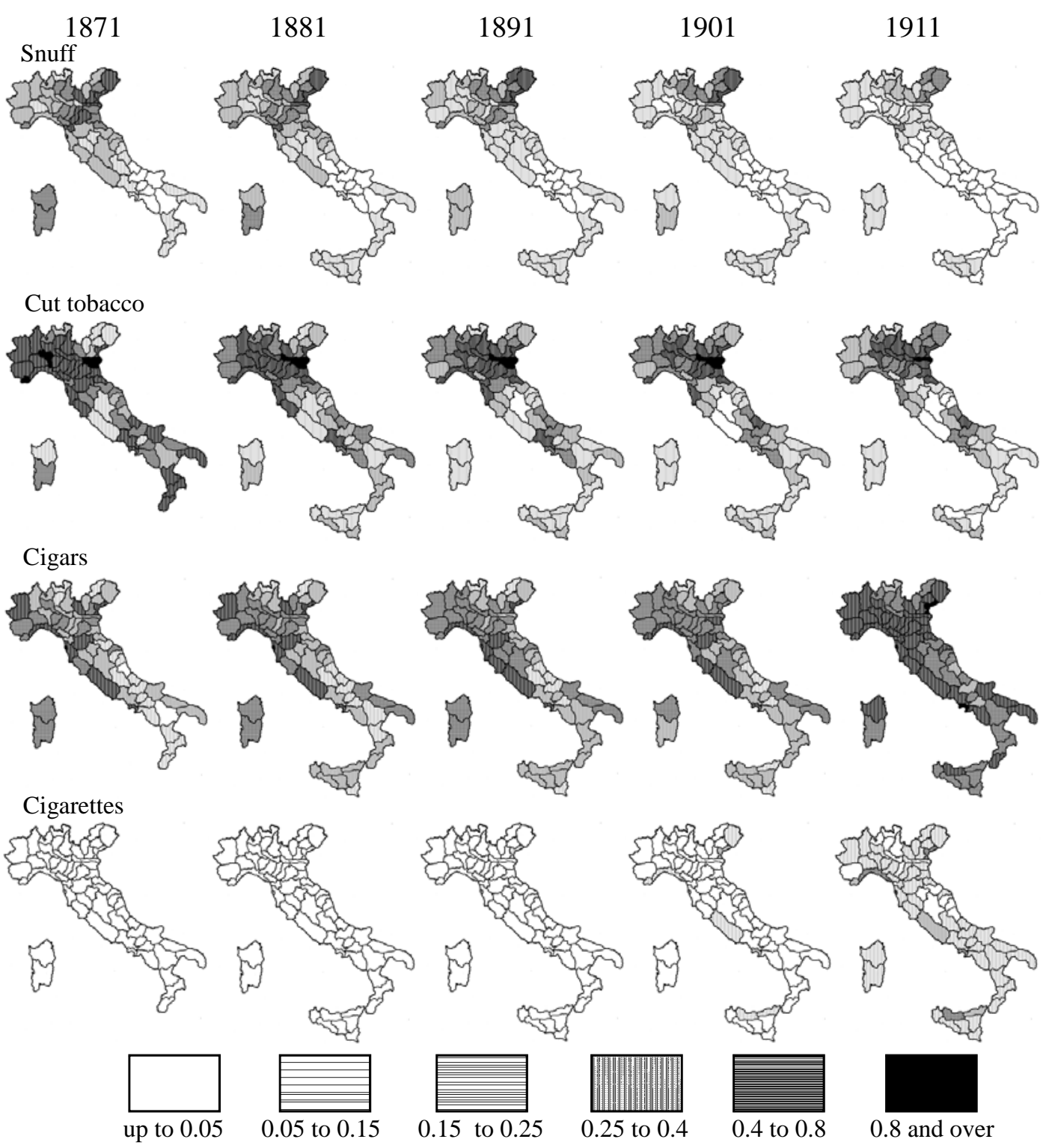

Figure 5: Tobacco consumption in Italian Provinces (kilograms per head). Source: see text.

more prevalent in the provinces containing large cities, consistent with the anecdotal view of cigar smoking as mainly an urban phenomenon. Figure 6 reports the real price (in 1911 lire) of the four product groups we consider. The prices of the four products, which were set by government decree, all change 


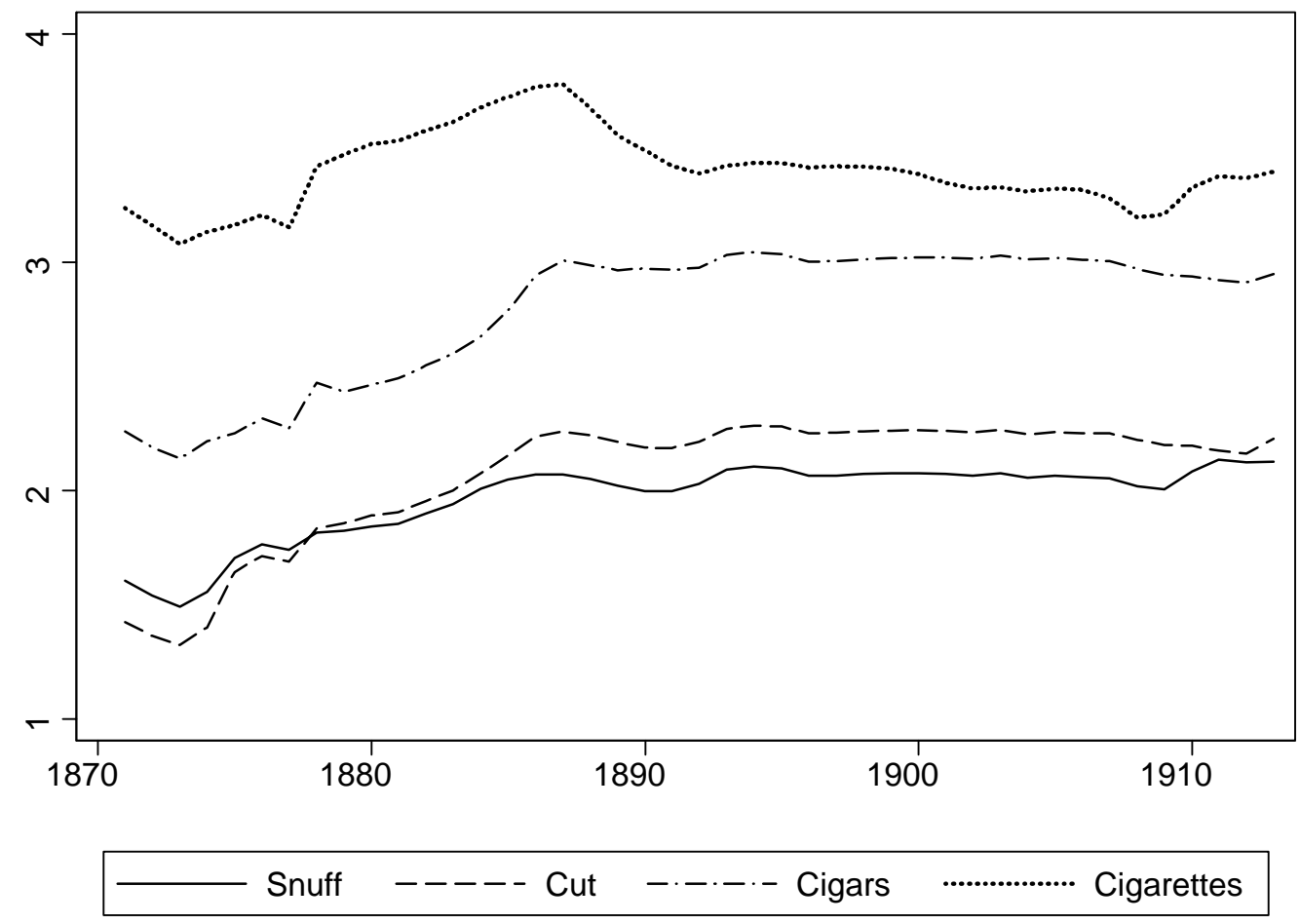

Figure 6: Real price of tobacco by main aggregates, 1871-1913 (mean of logarithm). Source: see text.

of course at the same time. ${ }^{24}$ Table 3 shows the estimates of equation (4) obtained by running four separate regressions, for snuff, cut tobacco, cigars and cigarettes. These are obtained using the the same system GMM and FE2SLS approaches used to derive the first and the third columns of Table $2 .^{25}$ In the first column, as we did in Section 4, we instrument lagged and forward consumption levels using lagged and future prices, both the own prices, and the prices of the other tobacco products. The similarity of the estimation of the GMM and the FE2SLS estimated coefficients indicate a measure of robustness of our results.

\footnotetext{
${ }^{24}$ Panel co-integration tests (with the algorithm proposed by Westerlund 2007), confirm that prices and quantities of the three product groups move in the same direction in the various provinces.

${ }^{25}$ The qualitative nature of the results does not change if cigars and cigarettes are aggregated into a single product group.
} 
Table 3: Estimation of equations (4) ${ }^{a}$

\begin{tabular}{|c|c|c|c|c|}
\hline & \multicolumn{2}{|c|}{ CUT } & \multicolumn{2}{|c|}{ SNUFF } \\
\hline & GMM & $\overline{\text { FE2SLS }}$ & GMM & $\overline{\text { FE2SLS }}$ \\
\hline$C_{t-1}^{J}$ & $\begin{array}{l}0.480^{*} \\
(0.008)\end{array}$ & $\begin{array}{l}0.489^{*} \\
(0.019)\end{array}$ & $\begin{array}{c}0.489^{*} \\
(0.022)\end{array}$ & $\begin{array}{c}0.492^{*} \\
(0.032)\end{array}$ \\
\hline$C_{t-1}^{N J}$ & $\begin{array}{c}0.073^{*} \\
(0.012)\end{array}$ & $\begin{array}{c}0.075^{*} \\
(0.020)\end{array}$ & $\begin{array}{l}-0.031^{*} \\
(0.010)\end{array}$ & $\begin{array}{c}-0.033^{*} \\
(0.017)\end{array}$ \\
\hline$C_{t+1}^{J}$ & $\begin{array}{l}0.507^{*} \\
(0.007)\end{array}$ & $\begin{array}{l}0.511^{*} \\
(0.020)\end{array}$ & $\begin{array}{c}0.511^{*} \\
(0.014)\end{array}$ & $\begin{array}{c}0.507^{*} \\
(0.030)\end{array}$ \\
\hline$C_{t+1}^{N J}$ & $\begin{array}{c}-0.089^{*} \\
(0.019)\end{array}$ & $\begin{array}{c}-0.073^{*} \\
(0.020)\end{array}$ & $\begin{array}{c}0.016 \\
(0.008)\end{array}$ & $\begin{array}{c}0.030^{*} \\
(0.014)\end{array}$ \\
\hline$P_{t}^{J}$ & $\begin{array}{c}-0.055^{*} \\
(0.017)\end{array}$ & $\begin{array}{l}-0.156^{*} \\
(0.025)\end{array}$ & $\begin{array}{c}-0.021^{*} \\
(0.010)\end{array}$ & $\begin{array}{c}-0.030^{*} \\
(0.011)\end{array}$ \\
\hline$P_{t}^{N J}$ & $\begin{array}{l}-0.062 \\
(0.039)\end{array}$ & $\begin{array}{c}0.037^{*} \\
(0.017)\end{array}$ & $\begin{array}{l}-0.016 \\
(0.018)\end{array}$ & $\begin{array}{c}0.004 \\
(0.009)\end{array}$ \\
\hline$T_{t}$ & $\begin{array}{c}0.031 \\
(0.018)\end{array}$ & $\begin{array}{c}0.009 \\
(0.009)\end{array}$ & $\begin{array}{c}0.014 \\
(0.008)\end{array}$ & $\begin{array}{l}0.011^{*} \\
(0.004)\end{array}$ \\
\hline \multirow[t]{3}{*}{$I_{t}$} & $\begin{array}{c}0.031 \\
(0.021)\end{array}$ & $\begin{array}{l}0.034^{*} \\
(0.017)\end{array}$ & $\begin{array}{c}0.015 \\
(0.014)\end{array}$ & $\begin{array}{c}-0.004 \\
(0.010)\end{array}$ \\
\hline & \multicolumn{2}{|c|}{ CIGARS } & \multicolumn{2}{|c|}{ CIGARETTES } \\
\hline & GMM & $\overline{\text { FE2SLS }}$ & GMM & $\overline{\text { FE2SLS }}$ \\
\hline$C_{t-1}^{J}$ & $\begin{array}{l}0.497^{*} \\
(0.012)\end{array}$ & $\begin{array}{l}0.408^{*} \\
(0.022)\end{array}$ & $\begin{array}{l}0.403^{*} \\
(0.018)\end{array}$ & $\begin{array}{l}0.480^{*} \\
(0.022)\end{array}$ \\
\hline$C_{t-1}^{N J}$ & $\begin{array}{c}0.052^{*} \\
(0.019)\end{array}$ & $\begin{array}{c}0.030 \\
(0.070)\end{array}$ & $\begin{array}{l}-0.025 \\
(0.050)\end{array}$ & $\begin{array}{c}-0.019 \\
(0.024)\end{array}$ \\
\hline$C_{t+1}^{J}$ & $\begin{array}{l}0.435^{*} \\
(0.020)\end{array}$ & $\begin{array}{l}0.551^{*} \\
(0.022)\end{array}$ & $\begin{array}{c}0.463^{*} \\
(0.025)\end{array}$ & $\begin{array}{l}0.490^{*} \\
(0.024)\end{array}$ \\
\hline$C_{t+1}^{N J}$ & $\begin{array}{c}-0.008 \\
(0.021)\end{array}$ & $\begin{array}{c}0.018 \\
(0.070)\end{array}$ & $\begin{array}{l}0.302^{*} \\
(0.082)\end{array}$ & $\begin{array}{c}0.021 \\
(0.025)\end{array}$ \\
\hline$P_{t}^{J}$ & $\begin{array}{c}-0.293^{*} \\
(0.039)\end{array}$ & $\begin{array}{l}-0.250^{*} \\
(0.035)\end{array}$ & $\begin{array}{c}-0.433^{*} \\
(0.061)\end{array}$ & $\begin{array}{l}-0.233^{*} \\
(0.022)\end{array}$ \\
\hline$P_{t}^{N J}$ & $\begin{array}{c}-0.059^{*} \\
(0.020)\end{array}$ & $\begin{array}{c}0.012 \\
(0.046)\end{array}$ & $\begin{array}{c}0.372^{*} \\
(0.1007)\end{array}$ & $\begin{array}{c}0.020 \\
(0.011)\end{array}$ \\
\hline$T_{t}$ & $\begin{array}{l}0.102^{*} \\
(0.019)\end{array}$ & $\begin{array}{l}0.053^{*} \\
(0.022)\end{array}$ & $\begin{array}{l}0.109^{*} \\
(0.035)\end{array}$ & $\begin{array}{c}0.068^{*} \\
(0.011)\end{array}$ \\
\hline$I_{t}$ & $\begin{array}{l}0.181^{*} \\
(0.048)\end{array}$ & $\begin{array}{c}0.094 \\
(0.061)\end{array}$ & $\begin{array}{l}0.179^{*} \\
(0.084)\end{array}$ & $\begin{array}{l}-0.008 \\
(0.022)\end{array}$ \\
\hline
\end{tabular}

${ }^{a}$ The dependent variable is the per capita consumption of the product heading the relevant columns. $C_{t}^{N J}=\sum_{K \neq J} C_{t}^{K}$ is the consumption of the other tobacco products. This and the other dependent variables are explained in the text, after equation (4). Numbers in parentheses denote absolute values of asymptotic standard errors. A * superscripts indicates that the estimated coefficient is significant at the $5 \%$ confidence level. Source: see text. 
In broad terms, the regressions are rather similar to each other and also to the regression for total consumption, shown in Table 2. In detail, intertemporal dependence of "own consumption", both backward and forward, is large and significant (both coefficients range from 0.4 to 0.51), indicating again rational addiction. Estimated price elasticities take plausible values, though here we see some differences among the products: all coefficients are statistically significant but close to 0 for cut-tobacco and snuff, higher for cigars and cigarettes. ${ }^{26}$ These differences among the products are reflected in the differences in income elasticities. As the first GMM-columns in Table 3 show, this is positive for cigars and cigarettes, and effectively 0 for snuff and cut tobacco. A tentative interpretation here is that cigars and cigarettes were a normal good, higher income and price decreases both leading to higher consumption. By contrast, snuff and fine-cut tobacco appear "necessities" of life, with their consumption determined by patterns of addiction, adjusting very sluggishly to exogenous changes. This of course tallies with the life-style image one associates to cigar smoking and, at the time, to cigarettes, whose novelty might have been seen, in contrast to the more traditional, and rural, snuff and fine-cut tobacco, as a sign of being in step with the times. Given the positive sign associated, in the first column, with the effect of illiteracy on the consumption of cigars and cigarettes, one would infer that this was more the case in relatively uneducated provinces. Seen in conjunction, Table 2 and Table 3 suggest that the positive income elasticity, the negative price elasticity, and the negative education elasticity of aggregate tobacco consumption are in fact driven in the main by the demand for cigars and for cigarettes. The estimates reported in the columns headed FE2SLS in Table 3 largely confirm the above findings. One possible exception is cigarettes: some of the coefficients estimated, among them the own price and the cross price elasticity, are now either reduced in size, or not significant.

Our tentative answer to the question of whether habit or addiction caused persistence of consumption hinges around the role of "other tobacco products" and the cross price elasticity. Two things need to be noticed. First, the coefficients for lagged and forward consumption of the other products are either

\footnotetext{
${ }^{26}$ The Arellano-Bond tests for first and second order serial-correlation performed after the GMM estimation yield the expected results and do suggest a sound econometric strategy. On the other hand, the result of the Hansen test for appropriateness of the set of instruments is less convincing than for the regression for the total quantity.
} 
statistically not different from 0 , or very close to 0 in value, with the exception, depending on the estimation procedure, of a positive effect of forward consumption of other tobacco products on the consumption of cigarettes. These coefficients are also significantly different from the "own" addiction coefficients. Secondly, the cross price elasticity is also close to 0, again cigarettes excepted. These two observations, taken together, lend reasonable support to the idea that the addictive nature of tobacco products is determined by consumption of the product itself, rather than nicotine or other substances in tobacco. They suggest, in other words, that nineteenth century Italians were using snuff, smoking a pipe, a cigarette or a cigar because they had done so in the past, having become habituated to the gestures and behaviours, and intended to continue to do so in the future, rather because they craved nicotine.

The last paragraph hints at differences in the determinants of consumption of cigarettes, relative to the other products. This might be due to their novel character which made them a substitute for cigars. Another obvious distinctive feature of cigarettes is the profound change in the pattern of consumption across the period. Cigarette consumption was essentially absent in 1871, and grew steadily across the period, ${ }^{27}$ going from $0.1 \%$ of the total quantity in 1871 consumed, to $18.6 \%$ in 1913 . This steady increase in consumption occurred over a period during which an important changed took place on the production side of cigarettes, with no corresponding change for the other products. We refer to the introduction of the Bonsack rolling machines (Brandt 2007, pp. $27 \mathrm{ff}$., Tate 1999, pp. 15-16, Hannah 2006, pp. 64-67) which allowed the Italian state monopoly to mechanise production at the beginning of the 1890s. (Ministero delle Finanze 1892, p. 39). Thus we end the paper by attempting to identify the cause of the introduction of the Bonsack machine in Italy. At a conceptual level, the introduction of a new machine, which changes the balance between fixed and variable costs, may be driven by two distinct, though not exclusive, factors: changes in demand or technological opportunities. If the demand for a product changes, for whatever reason, ${ }^{28}$ a stimulus is created, which might

\footnotetext{
${ }^{27} \mathrm{~A}$ simple time trend regression give a national growth rate of $13 \%$ per year, with a 0.984 $R^{2}$. By comparison the rest of tobacco consumption declined at a rate of about $0.2 \%$ per year.

${ }^{28}$ In one account, demand changed exogenously in the US at the time, which stimulated mechanisation. There, in contrast to Europe in general and Italy in particular, chewing
} 
increase the break-even point for capital items which incur high fixed costs, and so encourage the adoption of hitherto unsuitable technologies. On the other hand, the adoption decision might simply be the consequence of the appearance of a new cost reducing technology. In this narrative, changes in demand in the US, together with Duke's aggressive monopolistic behaviour (see Hannah 2006, p. 64-65), brought about the development improvement and adoption of Bonsack machine. Indeed, its construction is a direct consequence of the offer by the Allan \& Ginter company in Richmond, Virginia, of a $\$ 75,000$ prize to the inventor of a viable machine to roll cigarettes. Though Duke prevented competitors from taking advantage of the new machines, they were available in Europe, and their use determined substantial reductions in production costs. To the extent that the government lowered its prices in response, then quantity demanded increased without any change in the functional form of demand. To put it succinctly, in the first case we attribute the change in consumption to an exogenous shift in the demand schedule, to an exogenous shift in the cost schedule in the second case.

In order to identify the cause of the increase in cigarette consumption in Italy at the turn of the century, we use two complementary ways. The first is close in spirit to the Chow standard approach to structural breaks and assumes knowledge of information independent of the available data on the best date to partition the sample. First we split the sample in two parts, taking the year 1894 as the separation (using contiguous years as the split changes nothing of substance), and we estimate equation (4) in the two shorter panels. The results of this exercise are shown in the second and third columns of Table 4, next to column 1 which, for convenience, duplicates the first column of Table 3. The superscripts after a coefficient indicate whether it is significantly different from 0 (an asterisk), whether it is significantly different from the coefficient for the whole 1871-1913 period (a "+" sign, for columns 2 and 3), and whether the coefficients in the two subsamples are significantly different from each other (an "s" sign in the third column). The presence of several "+" and "s" superscripts does therefore indicate that from a statistical viewpoint there are some

was prevalent in the first part of the nineteenth century, but "the rapid urbanization of the late nineteenth century [changed the structure of demand and] gave cigarettes advantages over [...] chewing tobacco, [as] urban standards of decorum discouraged spitting, a necessary adjunct to tobacco chewing" (Tate, p. 17). 
Table 4: Splitting the period in two parts, 1871-94 and $1895-1913^{a}$

\begin{tabular}{|c|c|c|c|c|c|c|}
\hline & \multicolumn{3}{|c|}{ CUT } & \multicolumn{3}{|c|}{ SNUFF } \\
\hline & $\begin{array}{c}\text { whole period } \\
1871-1913 \\
\end{array}$ & $\begin{array}{c}\text { 1st part } \\
1871-1894 \\
\end{array}$ & $\begin{array}{c}\text { 2nd part } \\
\text { 1895-1913 }\end{array}$ & $\begin{array}{c}\text { whole period } \\
1871-1913 \\
\end{array}$ & $\begin{array}{c}\text { 1st part } \\
1871-1894 \\
\end{array}$ & $\begin{array}{c}\text { 2nd part } \\
1895-1913 \\
\end{array}$ \\
\hline$C_{t-1}^{J}$ & $\begin{array}{l}0.480^{*} \\
(0.008)\end{array}$ & $\begin{array}{c}0.466^{*+} \\
(0.009)\end{array}$ & $\begin{array}{c}0.569^{*+s} \\
(0.019)\end{array}$ & $\begin{array}{l}0.489^{*} \\
(0.022)\end{array}$ & $\begin{array}{c}0.471^{*+} \\
(0.026)\end{array}$ & $\begin{array}{c}0.541^{*+s} \\
(0.011)\end{array}$ \\
\hline$C_{t-1}^{N J}$ & $\begin{array}{l}0.073^{*} \\
(0.012)\end{array}$ & $\begin{array}{l}0.090^{*} \\
(0.015)\end{array}$ & $\begin{array}{l}0.053^{*} \\
(0.022)\end{array}$ & $\begin{array}{l}-0.031^{*} \\
(0.010)\end{array}$ & $\begin{array}{c}-0.030^{*} \\
(0.012)\end{array}$ & $\begin{array}{c}-0.011 \\
(0.009)\end{array}$ \\
\hline$C_{t+1}^{J}$ & $\begin{array}{l}0.507^{*} \\
(0.007)\end{array}$ & $\begin{array}{l}0.506^{*} \\
(0.009)\end{array}$ & $\begin{array}{c}0.478^{*+} \\
(0.021)\end{array}$ & $\begin{array}{l}0.511^{*} \\
(0.014)\end{array}$ & $\begin{array}{l}0.529^{*} \\
(0.018)\end{array}$ & $\begin{array}{l}0.467^{* s} \\
(0.011)\end{array}$ \\
\hline$C_{t+1}^{N J}$ & $\begin{array}{l}-0.089^{*} \\
(0.019)\end{array}$ & $\begin{array}{l}-0.103^{*} \\
(0.020)\end{array}$ & $\begin{array}{c}-0.009^{+s} \\
(0.030)\end{array}$ & $\begin{array}{c}0.016 \\
(0.008)\end{array}$ & $\begin{array}{c}0.005 \\
(0.011)\end{array}$ & $\begin{array}{c}0.004 \\
(0.009)\end{array}$ \\
\hline$P_{t}^{J}$ & $\begin{array}{l}-0.055^{*} \\
(0.017)\end{array}$ & $\begin{array}{l}-0.086^{*} \\
(0.021)\end{array}$ & $\begin{array}{c}0.082^{+s} \\
(0.044)\end{array}$ & $\begin{array}{l}-0.021^{*} \\
(0.010)\end{array}$ & $\begin{array}{l}-0.045 \\
(0.023)\end{array}$ & $\begin{array}{l}-0.007 \\
(0.006)\end{array}$ \\
\hline$P_{t}^{N J}$ & $\begin{array}{l}-0.062 \\
(0.039)\end{array}$ & $\begin{array}{l}-0.069 \\
(0.050)\end{array}$ & $\begin{array}{c}0.189^{*+s} \\
(0.066)\end{array}$ & $\begin{array}{l}-0.016 \\
(0.018)\end{array}$ & $\begin{array}{l}-0.030 \\
(0.028)\end{array}$ & $\begin{array}{l}-0.013 \\
(0.008)\end{array}$ \\
\hline$T_{t}$ & $\begin{array}{c}0.031 \\
(0.018)\end{array}$ & $\begin{array}{c}0.039 \\
(0.023)\end{array}$ & $\begin{array}{c}-0.059^{*+s} \\
(0.027)\end{array}$ & $\begin{array}{c}0.014 \\
(0.008)\end{array}$ & $\begin{array}{l}0.027^{*} \\
(0.011)\end{array}$ & $\begin{array}{c}0.008 \\
(0.004)\end{array}$ \\
\hline \multirow[t]{3}{*}{$I_{t}$} & $\begin{array}{c}0.031 \\
(0.021)\end{array}$ & $\begin{array}{c}0.037 \\
(0.039)\end{array}$ & $\begin{array}{l}-0.015 \\
(0.033)\end{array}$ & $\begin{array}{c}0.015 \\
(0.014)\end{array}$ & $\begin{array}{c}0.048 \\
(0.036)\end{array}$ & $\begin{array}{c}0.019 \\
(0.012)\end{array}$ \\
\hline & \multicolumn{3}{|c|}{ CIGARS } & \multicolumn{3}{|c|}{ CIGARETTES } \\
\hline & $\begin{array}{c}\text { whole period } \\
1871-1913\end{array}$ & $\begin{array}{c}\text { 1st part } \\
1871-1894\end{array}$ & $\begin{array}{c}\text { 2nd part } \\
1895-1913\end{array}$ & $\begin{array}{c}\text { whole period } \\
1871-1913\end{array}$ & $\begin{array}{c}\text { 1st part } \\
1871-1894\end{array}$ & $\begin{array}{c}\text { 2nd part } \\
1895-1913\end{array}$ \\
\hline$C_{t-1}^{J}$ & $\begin{array}{l}0.497^{*} \\
(0.012)\end{array}$ & $\begin{array}{c}0.466^{*+} \\
(0.015)\end{array}$ & $\begin{array}{c}0.581^{*+s} \\
(0.012)\end{array}$ & $\begin{array}{l}0.403^{*} \\
(0.018)\end{array}$ & $\begin{array}{l}0.400^{*+} \\
(0.021)\end{array}$ & $\begin{array}{l}0.451^{* s} \\
(0.008)\end{array}$ \\
\hline$C_{t-1}^{N J}$ & $\begin{array}{l}0.052^{*} \\
(0.019)\end{array}$ & $\begin{array}{l}0.102^{*} \\
(0.027)\end{array}$ & $\begin{array}{c}-0.098^{*+s} \\
(0.021)\end{array}$ & $\begin{array}{l}-0.025 \\
(0.050)\end{array}$ & $\begin{array}{l}-0.141^{*} \\
(0.054)\end{array}$ & $\begin{array}{c}0.077 \\
(0.044)\end{array}$ \\
\hline$C_{t+1}^{J}$ & $\begin{array}{c}0.435^{*} \\
(0.020)\end{array}$ & $\begin{array}{l}0.406^{*} \\
(0.027)\end{array}$ & $\begin{array}{l}0.438^{*} \\
(0.011)\end{array}$ & $\begin{array}{c}0.463^{*} \\
(0.025)\end{array}$ & $\begin{array}{c}0.463^{*} \\
(0.029)\end{array}$ & $\begin{array}{c}0.557^{*+s} \\
(0.010)\end{array}$ \\
\hline$C_{t+1}^{N J}$ & $\begin{array}{l}-0.008 \\
(0.021)\end{array}$ & $\begin{array}{l}-0.002 \\
(0.041)\end{array}$ & $\begin{array}{c}0.095^{*+s} \\
(0.021)\end{array}$ & $\begin{array}{l}0.302^{*} \\
(0.082)\end{array}$ & $\begin{array}{l}0.276^{*} \\
(0.118)\end{array}$ & $\begin{array}{l}-0.084 \\
(0.044)\end{array}$ \\
\hline$P_{t}^{J}$ & $\begin{array}{l}-0.293^{*} \\
(0.039)\end{array}$ & $\begin{array}{c}-0.501^{*+} \\
(0.060)\end{array}$ & $\begin{array}{c}-0.138^{* s} \\
(0.025)\end{array}$ & $\begin{array}{l}-0.433^{*} \\
(0.061)\end{array}$ & $\begin{array}{l}-0.557^{*} \\
(0.094)\end{array}$ & $\begin{array}{c}-0.217^{* s} \\
(0.031)\end{array}$ \\
\hline$P_{t}^{N J}$ & $\begin{array}{c}-0.059^{*} \\
(0.020)\end{array}$ & $\begin{array}{l}-0.039 \\
(0.067)\end{array}$ & $\begin{array}{c}-0.039^{*} \\
(0.011)\end{array}$ & $\begin{array}{c}0.372^{*} \\
(0.1007)\end{array}$ & $\begin{array}{l}0.315^{*} \\
(0.148)\end{array}$ & $\begin{array}{l}0.061^{*} \\
(0.030)\end{array}$ \\
\hline$T_{t}$ & $\begin{array}{l}0.102^{*} \\
(0.019)\end{array}$ & $\begin{array}{l}0.185^{*} \\
(0.038)\end{array}$ & $\begin{array}{c}0.008^{+s} \\
(0.007)\end{array}$ & $\begin{array}{l}0.109^{*} \\
(0.035)\end{array}$ & $\begin{array}{l}0.130^{*} \\
(0.048)\end{array}$ & $\begin{array}{c}-0.027^{*+s} \\
(0.014)\end{array}$ \\
\hline$I_{t}$ & $\begin{array}{l}0.181^{*} \\
(0.048)\end{array}$ & $\begin{array}{l}0.388^{*} \\
(0.111)\end{array}$ & $\begin{array}{l}0.038^{* s} \\
(0.016)\end{array}$ & $\begin{array}{c}0.179^{*} \\
(0.084)\end{array}$ & $\begin{array}{l}-0.159 \\
(0.179)\end{array}$ & $\begin{array}{c}-0.095^{*} \\
(0.028)\end{array}$ \\
\hline
\end{tabular}

${ }^{a}$ See Table 4 for description of the variables. The superscripts ${ }^{*},{ }^{+}$, and ${ }^{s}$ indicate that the estimated coefficient is significantly different at the $5 \%$ significance level from 0 , from the correspondent coefficient in the first column, and from the correspondent coefficient in the second column. Source: see text. 
differences between the estimated equations for the first period and the second, and for the whole period. From an economic viewpoint, however, these differences indicate small quantitative changes, by and large suggesting an absence of substantial large shift in consumer preferences following the adoption of the Bonsack machines. One possible noteworthy exception is the reversed sign of the illiteracy coefficient in the cigarette equation, which, while appearing positive in the whole period, is instead negative in the second part, indicating that, other things equal, better educated provinces consumed more cigarettes. This finding, however, must be taken with a pinch of salt, given the low level of cigarette consumption at the time.

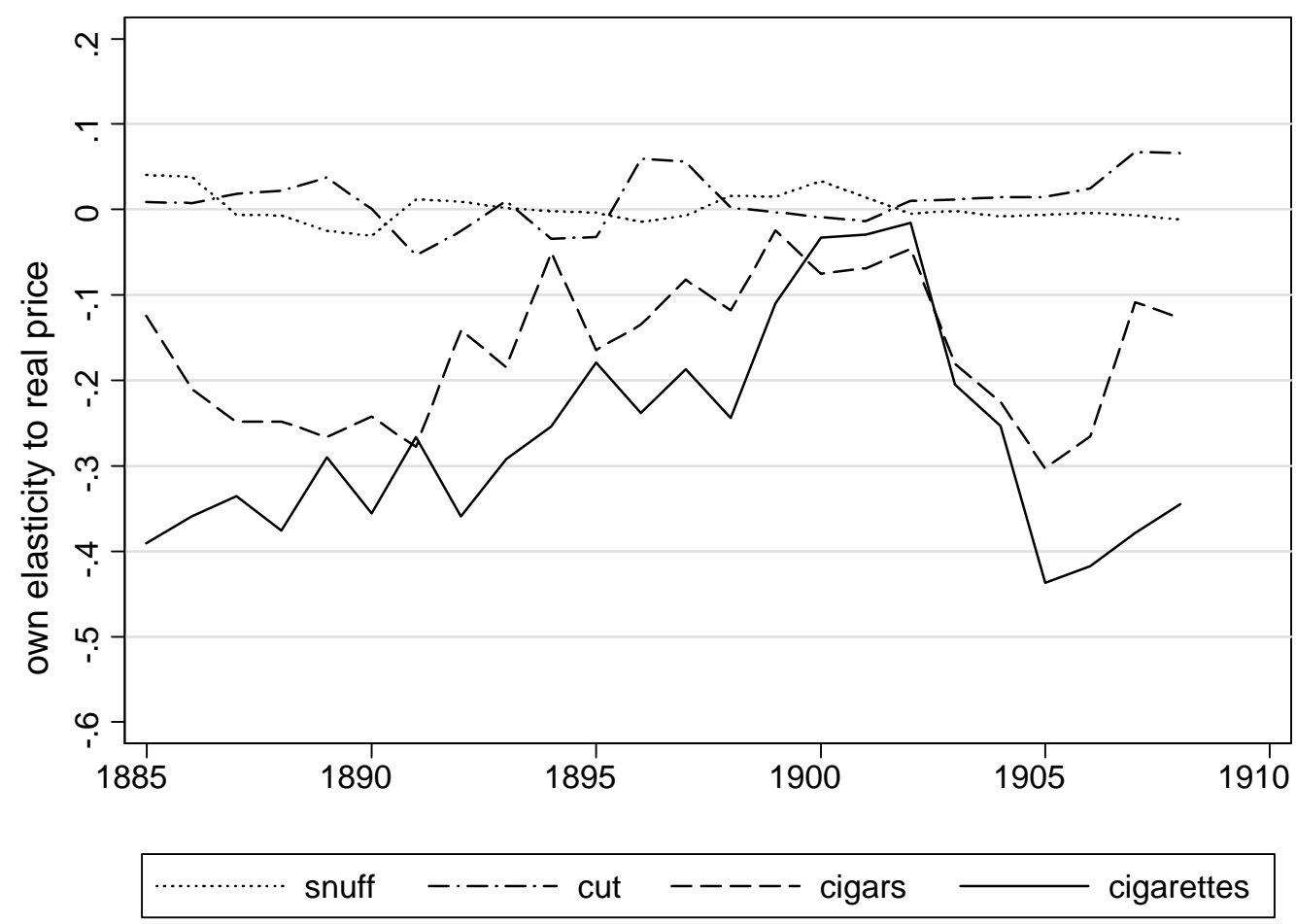

Figure 7: Rolling regression of own elasticity to price, 1885-1908. Source: see text.

The second way follows an approach that goes back at least to Kuznets (1928). We perform rolling regressions, with a 10 year symmetric moving window centred in $t$, with $t=1885,1886, \ldots, 1908$ starting thus in 1880 , well before 
the introduction of the Bonsack machines in Italy. In each regression we estimate equation (4) on a 10 year panel, using the same GMM procedure with which we obtained the first column in Table 3. The results are shown in Figure 7. It shows the estimates, for each regression, of the own price elasticity, for each product, in the period considered. Once again, while showing some time variability in the coefficients, the figure does not suggest any fundamental change in demand in the period. In view of this, we would conclude that the introduction of the Bonsack machine in the Italian tobacco industry was not driven by a change in demand, and therefore should be seen as a consequence of a shift in the supply schedule, in turn caused by the lower production cost which mechanisation determined.

\section{Concluding Remarks}

This paper analyses a new dataset collecting consumption of and expenditure on tobacco in Italy from 1871 to 1913. We find that the Becker and Murphy (1988) rational addiction model performs well at a time and in a country where there were no campaigns to dissuade the public from smoking. ${ }^{29}$ We also study the structure of demand for each of the four components of the total consumption of tobacco, snuff, fine-cut, cigars, and cigarettes. Our result indicate that the consumption of each specific product was more strongly affected by past and forward consumption of that product, and by that product's price than by the total past and forward consumption of tobacco and the price of alternatives tobacco products. This suggests that the addictive nature of tobacco products is determined by consumption of the product itself, rather than nicotine or other substances in tobacco. We conclude the paper by applying our econometric setup to study whether the mechanisation of production by the monopoly producer was a response to exogenous changes in demand, or to exogenous changes in technology. Our results suggest the latter.

\footnotetext{
${ }^{29}$ And indeed, their desirability aside, the liberal government of the time maintained a strong scepticism about the effectiveness of such campaigns, Prime Minister Giolitti refused to contemplate banning young people from smoking on the grounds that it "would have the immediate effect to make them all smoke, just to enjoy breaking the law with little risk of getting caught." (Atti Parlamentari 1907, p. 11800).
} 


\section{References}

Adda, Jérôme and Francesca Cornaglia (2006), "Taxes, cigarette consumption, and smoking intensity." American Economic Review, 96, 1013-1028.

Alston, Lee J, Ruth Dupré, and Tomas Nonnenmacher (2002), "Social reformers and regulation: The prohibition of cigarettes in the United States and Canada." Explorations in Economic History, 39, 425-445.

Anderson, T W and Cheng Hsiao (1981), "Estimation of dynamic models with error components." Journal of the American Statistical Association, 76, 598-606.

Andersson, Linda, Mikael Bask, and Maria Melkersson (2006), "Economic man and the consumption of addictive goods: The case of two goods." Substance Use 8 Misuse, 41, 453-466.

Arellano, Manuel and Olympia Bover (1995), "Another look at the instrumental variable estimation of error-component models." Journal of Econometrics, 68, 2951.

Aristei, David and Luca Pieroni (2008), "A double-hurdle approach to modelling tobacco consumption in Italy." Applied Economics, 40, 2463-2476.

Atkinson, Anthony B and J L Skegg (1973), "Anti-smoking publicity and the demand for tobacco in the UK." Manchester School, 41, 265-282.

Atti Parlamentari (1878), Legislatura XIII, Sessione 1878, Documenti, Progetto di Legge 38a. Camera dei Deputati, Rome, Italy.

Atti Parlamentari (1907), Legislatura XXII, 1a Sessione, Discussioni, Tornata del 9 febbraio. Camera dei Deputati, Rome, Italy.

Auld, M Christopher and Paul Grootendorst (2004), "An empirical analysis of milk addiction." Journal of Health Economics, 23, 1117-1133.

Baltagi, Badi and James M Griffin (2001), "The econometrics of rational addiction: The case of cigarettes." Journal of Business 85 Economic Statistics, 19, 449-454.

Becker, Gary S, Michael Grossman, and Kevin M Murphy (1994), "An empirical analysis of cigarette addiction." American Economic Review, 84, 396-418.

Becker, Gary S and Kevin M Murphy (1988), "A theory of rational addiction." Journal of Political Economy, 96, 675-700. 
Benowitz, Neal L, Herve Porchet, Lewis Sheiner, and Peyton Jacob III (1988), "Nicotine absorption and cardiovascular effects with smokeless tobacco use: Comparison with cigarettes and nicotine gum." Clinical Pharmacology and Therapeutics, 44, $23-28$.

Boria, Pietro (2008), Il sistema tributario. UTET, Torino, Italy.

Brandt, Allan M (2007), The Cigarette Century: The Rise, Fall, and Deadly Persistence of the Product that Defined America. Basic Books, Cambridge, MA.

Brunetti, Alessandro, Emanuele Felice, and Giovanni Vecchi (2011), "Reddito." In In ricchezza e in povertà. Il benessere degli italiani dall'Unità a oggi (Giovanni Vecchi, ed.), 209-234, Il Mulino, Bologna.

Chaloupka, Frank J (1991), "Rational addictive behavior and cigarette smoking." Journal of Political Economy, 99, 722-742.

Chaloupka, Frank J and Kenneth E Warner (2000), "The economics of smoking." In Handbook of Health Economics. Volume 1, Part B (Anthony J Culyer and Joseph P Newhouse, eds.), 1539-1627, North-Holland, Amsterdam.

Chandler, Alfred D (1977), The Visible Hand. The Managerial Revolution in American Business. Harvard University Press, Cambridge, Massachusetts.

Ciccarelli, Carlo (2012), "The consumption of tobacco in Italy: National and regional time series, 1871-1913." Rivista di Storia Economica, 28, 409-452.

Ciccarelli, Carlo, Gianni De Fraja, and Jesse Matheson (2012), "Was the Italian government a profit maximiser?" University of Leicester. Presented at the 2012 EARIE conference.

Ciccarelli, Carlo and Stefano Fenoaltea (2013), "Through the magnifying glass: provincial aspects of industrial growth in post-Unifcation Italy." Economic History Review, 66, 57-85.

Clough, Shepard B and Carlo Livi (1956), "Economic growth in Italy: An analysis of the uneven development of north and south." Journal of Economic History, 16, 334-349.

Deaton, Angus (1997), The Analysis of Household Surveys. The Johns Hopkins University Press, Baltimore. 
DeCicca, Philip, Donald Kenkel, and Alan Mathios (2002), "Putting out the fires: Will higher taxes reduce the onset of youth smoking?" Journal of Political Economy, 110, 144-169.

Eckaus, Richard S (1961), "The North-South differential in Italian economic development." Journal of Economic History, 21, 285-317.

Engleman, Steve (1987), "The impact of mass media anti-smoking publicity." Health Promotion, 2, 63-74.

Escario, Jose Julian and Jose Alberto Molina (2001), "Testing for the rational addiction hypothesis in Spanish tobacco consumption." Applied Economics Letters, $8,211-215$.

Farrelly, Matthew C, Terry F Pechacek, and Frank J Chaloupka (2005), "The impact of tobacco control program expenditures on aggregate cigarette sales: 1981-2000." Journal of Health Economics, 22, 843-859.

Felice, Emanuele (2011), "Regional value added in Italy, 1891-2001, and the foundation of a long-term picture." Economic History Review, 64, 929-950.

Felice, Emanuele (2012), "Regional convergence in Italy, 1891-2001: Testing human and social capital." Cliometrica, 6, 267-306.

Fenoaltea, Stefano (1986), "Public works construction in Italy, 1861-1913." Rivista di Storia Economica, International Issue, 1-33.

Fenoaltea, Stefano (2002), "Production and consumption in post-unification Italy; new evidence, new conjectures." Quaderni dell'Ufficio Ricerche Storiche, Banca d'Italia, 5, 54-55.

Fenoaltea, Stefano (2005), "The growth of the Italian economy, 1861-1913: Preliminary second-generation estimates." European Review of Economic History, 8, 273-312.

Frenk, Hanan and Reuven Dar (2000), A Critique of Nicotine Addiction. Kluwer Academic, Norwell, Mass.

Frieden, Thomas R, Farzad Mostashari, Bonnie D Kerker, Nancy Miller, Anjum Hajat, and Martin Frankel (2005), "Adult tobacco use levels after intensive tobacco control measures: New York City, 2002-2003." American Journal of Public Health, 95, 1016-1023. 
Gilman, Stephen E, Laurie T Martin, David B Abrams, Ichiro Kawachi, Laura Kubzansky, Eric B Loucks, Richard Rende, Rima Rudd1, and Stephen L Buka (2008), "Educational attainment and cigarette smoking: A causal association?" International Journal of Epidemiology, 37, 615-624.

Giskes, K, A E Kunst, J Benach, C Borrell, G Costa, E Dahl, J A A Dalstra, B Federico, U Helmert, K Judge, E Lahelma, K Moussa, P O Ostergren, S Platt, R Prattala, N K Rasmussen, and J P Mackenbach (2005), "Trends in smoking behaviour between 1985 and 2000 in nine European countries by education." Journal of Epidemiology and Community Health, 59, 395-401.

Gospodinov, Nikolay and Ian Irvine (2005), "A 'long march' perspective on tobacco use in Canada." Canadian Journal of Economics, 38, 366-393.

Gruber, Jonathan and Botond Köszegi (2001), "Is addiction "rational"? theory and evidence." Quarterly Journal of Economics, 116, 1261-1303.

Hannah, Leslie (2006), "The Whig fable of American Tobacco, 1895-1913." Journal of Economic History, 66, 42-73.

ISTAT (1958), Sommario di Statistiche Storiche Italiane, 1861-1955. Istituto Centrale di Statistica, Rome, Italy.

Jones, Andrew and Margherita Giannoni Mazzi (1996), "Tobacco consumption and taxation in Italy: An application of the QUAIDS model." Applied Economics, 28, 595-603.

Kuznets, Simon (1928), "On moving correlation of time sequences." Journal of the American Statistical Association, 23, 121-136.

Lance, Peter M, John S Akin, William H Dow, and Chung-Ping Loh (2004), "Is cigarette smoking in poorer nations highly sensitive to price? evidence from Russia and China." Journal of Health Economics, 23, 173-189.

Lee, Jie-Min (2007), "The synergistic effect of cigarette taxes on the consumption of cigarettes, alcohol and betel nuts." BMC Public Health, 7, 121.

Luciani, Luciano (2006), "Il contrabbando sulle coste del mar Tirreno e a Napoli, dall'Unitá d'Italia al 1950." Il Contrabbando sulle coste del Tirreno ed a Napoli (1950-1985). Atti del convegno organizzato dal Museo Storico della Guardia di Finanza. http://www.gdf.gov.it/repository/ContentManagement/ information/P5778678\%/Contrabbando \_Coste\_Tirreno.pdf?download=1. 
Manera, Giovanni (1963), La domanda di tabacco in Italia. Giuffrè editore, Milan, Italy.

Ministero delle Finanze (1892), Relazione e bilancio industriale 1890-1891. Direzione generale delle gabelle, Azienda dei tabacchi, Rome, Italy.

Mortara, Giorgio (1913), "Numeri indici dello stato e del progresso economico delle regioni italiane." Giornale degli Economisti e Rivista di Statistica, 47, 17-29.

Nguyen, Lien, Gunnar Rosenqvist, and Markku Pekurinen (2012), "Demand for tobacco in Europe. An econometric analyis for 11 countries." Discussion Paper PPACTE Project. Report 6/2012, National Institute for Health and Welfare, Helsinki, Finland.

Pierani, Pierpaolo and Silvia Tiezzi (2009), "Addiction and interaction between alcohol and tobacco consumption." Empirical Economics, 37, 1-23.

Plebano, Achille (1899), Storia della finanza italiana. Dalla costituzione del nuovo regno alla fine del secolo XIX. Volume primo. Dal 1861 al 1876. Roux Frassati e Co., Turin, Italy.

Richter, Patricia, Knachelle Hodge, Stephen Stanfill, Liqin Zhang, and Clifford Watson (2008), "Surveillance of moist snuff: Total nicotine, moisture, $\mathrm{pH}$, un-ionized nicotine, and tobacco-specific nitrosamines." Nicotine and Tobacco Research, 10, $1645-1652$.

Richter, Patricia and Francis W Spierto (2003), "Surveillance of smokeless tobacco nicotine, $\mathrm{pH}$, moisture, and unprotonated nicotine content." Nicotine and Tobacco Research, 5, 885-889.

Rogeberg, Ole (2004), "Taking absurd theories seriously: Economics and the case of rational addiction theories." Philosophy of Science, 71, 263-285.

Roodman, David (2009), "A note on the theme of too many instruments." Oxford Bullettin of Economics and Statistics, 71, 135-158.

Schneider, Lynne, Benjamin Klein, and Kevin M Murphy (1981), "Governmental regulation of cigarette health information." Journal of Law and Economics, 24, $575-612$. 
Sloan, Frank A, V Kerry Smith, and Donald H Taylor, Jr (2002), "Information, addiction, and 'bad choices': Lessons from a century of cigarettes." Economics Letters, 77, 147-155.

Società anonima per la regìa cointeressata dei tabacchi (1881), Risposte all'interrogatorio della commissione d'inchietsa sui tabacchi nel regno d'Italia. Tipografia Bodoniana, Rome, Italy.

Sumner, Michael T (1971), "The demand for tobacco in the UK." Manchester School, $39,23-36$.

Tate, Cassandra (1999), Cigarette Wars: The Triumph of the Little White Slaver. Oxford University Press, Oxford.

Tiezzi, Silvia (2005), "An empirical analysis of tobacco addiction in Italy." The European Journal of Health Economics, 6, 233-243.

Vetritto, Giovanni (1997), La parabola di un'industria di stato. Marsilio Editori, Venice, Italy.

Warner, Kenneth E (1977), "The effects of the anti-smoking campaign on cigarette consumption." American Journal of Public Health, 67, 645-650.

Westerlund, Joakim (2007), "Testing for error correction in panel data." Oxford Bullettin of Economics and Statistics, 69, 709-748. 


\section{Appendix}

This appendix documents the sources used for the statistical reconstruction of the business tax variable used in this paper to proxy GDP at the provincial level for the years 1871-1913. The appendix also lists the sources used to estimate the percentage of illiterates over total population. Ciccarelli (2012) contains an exhaustive account on the sources for the remaining variables (tobacco, cost of living index, and population) used in this paper.

\section{Business Tax}

The original sources include under the heading "Business Taxes" a wide set of different elements. For reasons indicated in the main text, the business tax variable used in the empirical part of the paper was obtained by selecting three elements, namely the "Tassa di Bollo", the "Tassa di registro", and the "Tassa in Surrogazione del Bollo e del Registro" (that in the years 1871-1883 appears in the sources under the heading "Tassa sulle Società").

The data for the initial period (1871-1883) are from Ministero delle finanze, $A n$ nuario del Regno d'Italia, ad annum; (the data for the year 1875 are, for instance, taken from pp. 124-131 of Annuario del Regno d'Italia, 1876, sum of the provincial figures reported in the three columns with heading "Società", "Registro", and "Bollo"). The data for the first semester of 1884 and for the fiscal years 1884-85 to 1897-98 are from Ministero delle finanze, Relazione sulla amministrazione del demanio e delle tasse sugli affari per gli esercizi finanziari, ad annum; (the data for the year 1897-98 are, for instance, taken from Relazione sulla amministrazione del demanio e delle tasse sugli affari per gli esercizi finanziari, 1897-98, pp. 84-87, sum of the figures reported in the three columns with heading "Tasse di registro", "Tasse di bollo", and "Tasse in surrogazione del bollo e del registro"). The data for the fiscal years 1898-99 to 1913-14 are finally from Ministero delle finanze, Bollettino di statistica e legislazione comparata, ad annum; (the data for the year 1904-05 are, for instance, taken from Bollettino di statistica e legislazione comparata, 1904-05, pp. 1086-89, sum of the figures reported in the three columns with heading "Tasse di registro", "Tasse di bollo", and "Tasse in surrogazione del bollo e del registro").

\section{Illiteracy}

The data on illiterates for 1871 are from Censimento 1871, vol. 2, Introduzione, pp. B-I; those for 1881 are from Censimento 1881, vol. 2, pp. 587-598; figures for 
1901 are from Censimento 1901, vol. 2, pp. 268-319; figures for 1911 are finally from Censimento 1911, vol. 2; pp. 555-620. The 1871-1913 time series at the provincial level were then obtained by linear interpolation, separately by province, of the 1871 , 1881, 1901, and 1911 benchmark data.

\section{References}

Ministero delle Finanze (various years), Annuario del Regno d'Italia. Ministero delle Finanze, Rome, Italy.

Ministero delle Finanze (various years), Bollettino di statistica e legislazione comparata. Ministero delle Finanze, Roma, Italy.

Ministero delle Finanze (various years), Relazione sulla amministrazione del demanio e delle tasse sugli affari per gli esercizi finanziari. Ministero delle Finanze, Roma, Italy.

Ministero di Agricoltura, Industria e Commercio (1874-76), Popolazione. Censimento 31 dicembre 1871. 3 voll. Direzione Generale della Statistica, Rome, Italy.

Ministero di Agricoltura, Industria e Commercio (1883-85), Censimento della popolazione del Regno d'Italia al 31 dicembre 1881. 3 voll. Direzione Generale della Statistica, Rome, Italy.

Ministero di Agricoltura, Industria e Commercio (1902-04), Censimento della popolazione del Regno d'Italia al 10 febbraio 1901. 5 voll. Direzione Generale della Statistica, Rome, Italy.

Ministero di Agricoltura, Industria e Commercio (1914-16), Ufficio del censimento. Censimento della popolazione del Regno d'Italia al 10 giugno 1911. 7 voll. Direzione Generale della Statistica, Rome, Italy. 